\title{
Galling phenomena in metal forming
}

\author{
Kuniaki DOHDA ${ }^{1, *}$, Masahito YAMAMOTO ${ }^{1,2}$, Chengliang HU ${ }^{3, *}$, Laurent DUBAR ${ }^{4}$, Kornel F. EHMANN $^{1}$ \\ ${ }^{1}$ Department of Mechanical Engineering, Northwestern University, Evanston, IL 60208-3111, USA \\ ${ }^{2}$ Manufacturing Engineering Center, NSK Ltd., Fujisawa-Shi 251-8501, Japan \\ ${ }^{3}$ Institute of Forming Technology and Equipment, School of Materials and Engineering, Shanghai Jiao Tong University, \\ Shanghai 200240, China \\ ${ }^{4}$ LAMIH UMR CNRS 8201, Université Polytechnique Hauts-de-France, Valenciennes Cedex 959313, France \\ Received: 17 March 2020 / Revised: 05 July 2020 / Accepted: 07 July 2020 \\ (C) The author(s) 2020.
}

\begin{abstract}
Galling phenomena in metal forming not only affect the quality of the engineered surfaces but also the success or failure of the manufacturing operation itself. This paper reviews the different galling conditions in sheet and bulk metal forming processes along with their evolution and the effects of temperature on galling. A group of anti-galling methods employed to prevent galling defects are also presented in detail. The techniques for quantitatively measuring galling are introduced, and the related prediction models, including friction, wear, and galling growth models, are presented to better understand the underlying phenomena. Galling phenomena in other processes similar to those occurring in metal forming are also examined to suggest different ways of further studying galling in metal forming. Finally, future research directions for the study of galling in metal forming are suggested.
\end{abstract}

Keywords: galling; metal forming; friction; wear; adhesion; anti-galling

\section{Introduction}

Galling is a phenomenon in which the frictional force abruptly increases under specific conditions at the contact surface due to microscopic welding $[1,2]$. The term has been used to describe different types of surface damage that occur during practical applications in mechanical engineering systems [3-5]. Relatively limited galling can be observed in bearings and gears, for example, where it appears as scuffing or scoring on the accompanying surfaces. Galling has been recognized as a form of seizure on frictional surfaces that have become thermally or mechanically unstable [6-9]. Furthermore, several terms that attempt to describe the progress of surface damage to some extent have been proposed to describe galling, such as lubrication failure, micro-welding, pick-up, and build-up.

This article focuses on galling in metal forming. Galling phenomena between the tool and workpiece lead to a sharp increase in the forming load, fatal damage of the product surface, and severe wear of the tools. In metal forming, the mechanisms at the interface are quite complicated because the surface area increases due to bulk deformation, and the interface structure of the lubricant, oxide film, etc. greatly changes. Many factors are influencing galling, including deformation degree, tool surface roughness, lubricating film, and interface temperature [10].

Galling in metal forming is, in general, an unclear tribological issue in the process design stage that influences the success or failure of a new process. In real mass production, if mild galling appears on tools, an early change of tool before rapid wear

* Corresponding authors: Kuniaki DOHDA, E-mail: dohda.kuni@northwestern.edu; Chengliang HU, E-mail: clhu@sjtu.edu.cn 
occurs is essential. Understanding the mechanisms underlying galling will enable control of the friction between the tool and workpiece, allowing for a high level of certainty in process design in the initial stages.

Many researchers have conducted fundamental investigations on the mechanisms of galling conditions, establishment of testing methods for assessing galling resistance performance, and the development of new anti-galling technologies [11]. In recent years, there is an ever-increasing demand for the quantitative elucidation of galling mechanisms and their generation conditions in sheet metal and bulkforming of high strength steels (HSS) and high strength aluminum alloys (HSAA). The quantitative roles of various friction factors affecting the formation process of the surface transfer layer and the galling phenomena have been clarified [12]. In the research area of new lubricant development, the forming process design of a product does not change, but the galling phenomena are easy to find. Therefore, quantitative analysis of galling mechanisms is also important for synthesizing an environment-friendly lubricant to substitute the conventional one in metal forming.

In this review, to better understand galling phenomena in metal forming, the actual galling conditions clarified by many researchers are reviewed. In addition, countermeasures against galling occurrence that comprise advanced processes developed in recent years are summarized. Most importantly, methods for predicting galling and studies to detect galling during processing are introduced.

\section{Galling phenomena}

To provide an overview of galling in both sheet metal and bulk metal forming, the phenomenon that leads to its occurrence and its status under different processing conditions are described. Furthermore, the process of galling is explained, and the effects of temperature on galling are discussed.

As shown in Table 1, the dominant factors and values that influence galling vary considerably between metal forming operations [13]. Galling status is experimentally clarified by measuring the following parameters: (1) contact pressure; (2) relative sliding velocity and distance between tool and workpiece; (3) heat generated by friction; (4) heat generation due to plastic deformation; (5) direct contact conditions between the tool and workpiece, which are affected by the newly generated surface of the deformed workpiece, surface roughness, and hardness of the tool and workpiece; and (6) lubricant film thickness at the interface. The tribological system for each forming process is complex and different as it depends on the process conditions. For example, an increase in forming speed reduces heat transfer to the tool but increases frictional heat generated by workpiece deformation. To investigate the tribological behavior in metal forming including galling, various basic tribometers have been developed and used for evaluation [14]. By considering the levels of these influencing factors and their combined effects in each process, the actual galling appearance in different cases will be summarized.

\subsection{Sheet metal forming}

In the last decades, HSS sheets and HSAA plates have been increasingly adopted for automotive body parts to achieve both weight reduction and collision safety. The increased strength of the sheet

Table 1 Tribological conditions in metal forming processes. Reproduced with permission from Ref. [13], (C) ASME 2004.

\begin{tabular}{ccccc}
\hline Process factor & Sheet forming & Drawing/ironing & Rolling/rotary forming & Forging/extrusion \\
\hline Pressure $(\mathrm{MPa})$ & $1-100$ & $100-1,000$ & $100-1,000(1-3)$ & $100-3,000$ \\
$\left(\right.$ Ratio, $\left.p / Y^{*}\right)$ & $(0.1-1)$ & $(1-2)$ & & $(1-5)$ \\
Velocity $(\mathrm{m} / \mathrm{s})$ & $10^{-3}-10^{-1}$ & $10^{-2}-10^{2}$ & $10^{-2}-10\left(0-10^{-1}\right)$ & $10^{-3}-10^{-1}$ \\
$\begin{array}{c}\text { Relative rate) } \\
\text { Bulk temperature, }\end{array}$ & $\left(0-10^{-2}\right)$ & $\left(10^{-2}-10^{2}\right)$ & R.T. $\sim 200$ & R.T. 400 \\
$T_{\mathrm{b}}\left({ }^{\circ} \mathrm{C}\right)$ & R.T. $\sim 150$ & R.T. $\sim 300$ & or warm/hot Temp. & or warm/hot Temp. \\
$\begin{array}{c}\text { Surface expansion } \\
\text { rate, } A / A_{0^{* *}}\end{array}$ & $0.5-1.5$ & $1-2$ & $1-2$ & $1-100$ \\
\hline
\end{tabular}

Note: $Y^{*}$, yield stress of workpiece; $A / A_{0^{* *}}$, rate of workpiece surface area after to before process. 
material leads to a high load on the tool during forming, and as a result, the problem of galling becomes more pronounced [15-17].

In cold stamping of a steel sheet with a grade exceeding $590 \mathrm{MPa}$, the contact pressure reaches $800 \mathrm{MPa}$ locally, and the tool surface is easily seized and damaged in the case of a normal tool steel without any hard coating, as shown in Fig. 1(a) [18]. Because of the high local pressure, the flanges and bead parts are the regions where damage is commonly found. In cold bending of a galvanized steel sheet with a grade of 1,180 $\mathrm{MPa}$, adhesion occurs due to sliding with a velocity of $175 \mathrm{~mm} / \mathrm{s}$ [19], as illustrated in Fig. 1(b).

Generally, bending tests are used to evaluate the durability and adhesion of hard coatings on the tool to prevent direct contact between the tool and the workpiece. In the cold/warm deep drawing process of square cups with a forming speed of $3 \mathrm{~mm} / \mathrm{s}$ using a $590 \mathrm{MPa}$ steel, the effect of the tool coating and lubricant on the occurrence of adhesion has been analyzed, and the results have shown that forming at elevated temperatures tends to lead to galling [5].

Typical examples of surface damage in hot stamping of aluminum are presented in Fig. 2(a) [20]. In the hot strip drawing test of an Al-Si coated HSS sheet, an area of severe abrasive wear is found that precedes a thick layer of compaction

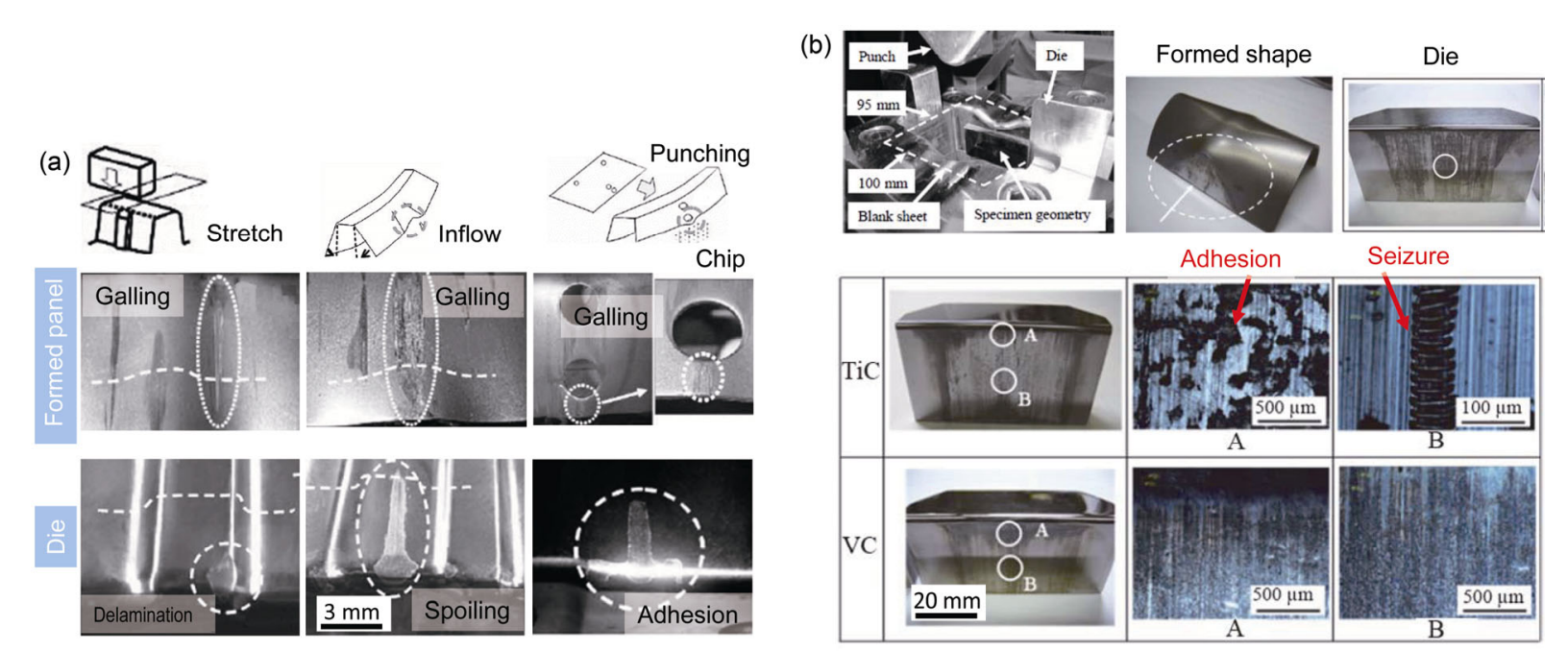

galling at higher temperatures $\left(>600{ }^{\circ} \mathrm{C}\right)$ while adhesive wear is dominant at lower temperatures $\left(<600{ }^{\circ} \mathrm{C}\right)$, as shown in Fig. 2(b) [21].

\subsection{Bulk metal forming}

In the combined forward and backward extrusion process, galling easily occurs on the sizing lands of the punch in backward extrusion and on the die in forward extrusion under dry conditions after three extrusion cycles [22], as shown in Fig. 3. High friction is generated at the interface between the workpiece and tooling. Once even a small adhesion damage is initiated on the tooling, more serious galling forms under the large surface expansion in bulk-forming. In the backward extrusion process with a reduction in the cross-sectional area of $50 \%$ under an initial punching speed of $150-200 \mathrm{~mm} / \mathrm{s}$, galling appears at the bottom of the punches where the relative sliding velocity is high and at the inner surfaces of the cup because this portion undergoes the largest surface area expansion [23], as shown in Fig. 4. To observe the process of galling generation, a rotating extrusion test with a conic punch was proposed. Scratches on the punch were observed and the frictional force was measured (Fig. 5) [24]. Two stages, including compression with large bulk deformation and sliding under a holding pressure, were carried out in the sliding compression test, in which sliding plates

Fig. 1 Galling appearance in high-strength-steel forming. (a) Example of galling damage in sheet forming [18]. Reproduced with permission from Ref. [18], (C) The Japan Society for Technology of Plasticity 2007. (b) Observation of galling during fundamental tests. Reproduced with permission from Ref. [19], (C) The Japan Society for Technology of Plasticity 2015. 
(a)

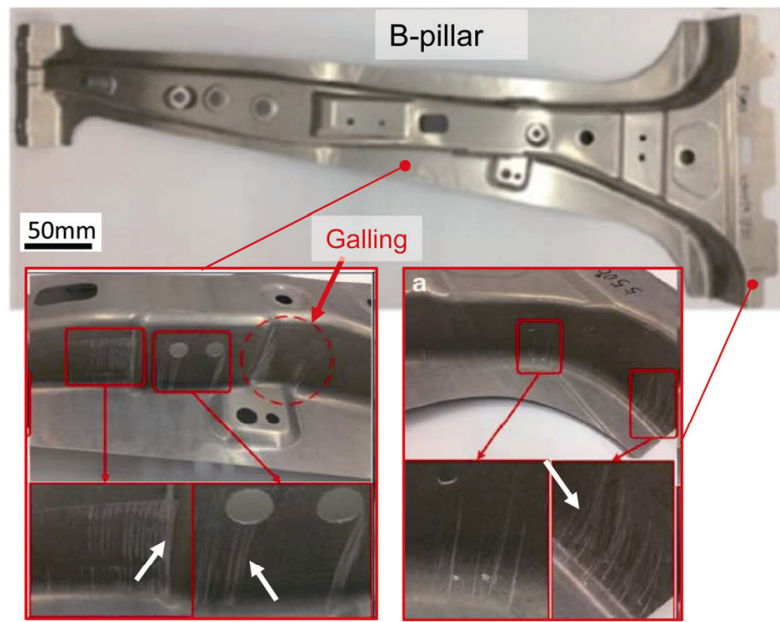

(b)

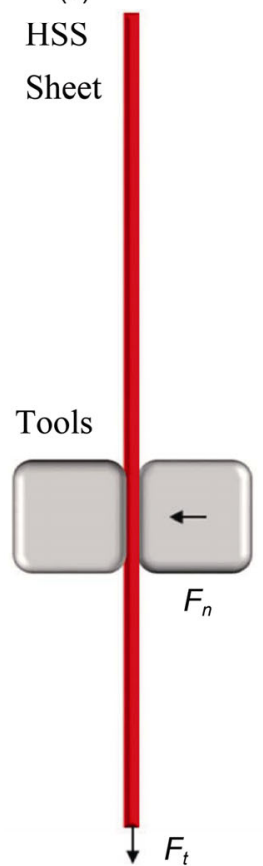

$700{ }^{\circ} \mathrm{C}$
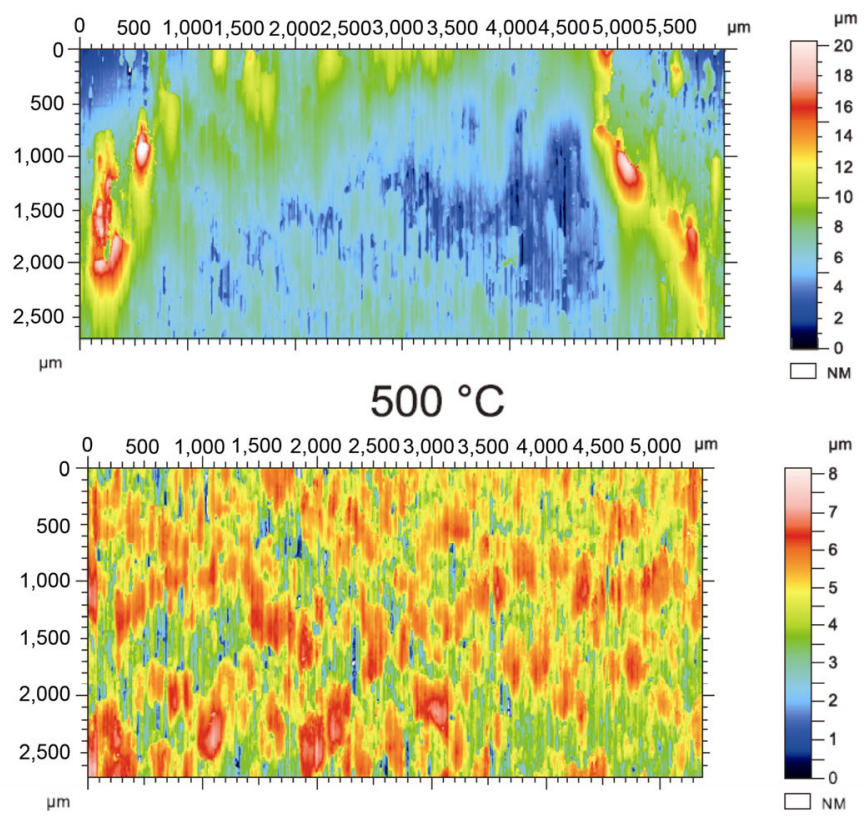

Fig. 2 Galling appearance in sheet forming at elevated temperatures. (a) Surface failure of AA6061 in hot stamping. Reproduced with permission from Ref. [20], (C) Springer Nature 2018. (b) Drawn surface appearance on coated steel sheet at elevated temperatures. Reproduced with permission from Ref. [21], C Elsevier B.V. 2018.
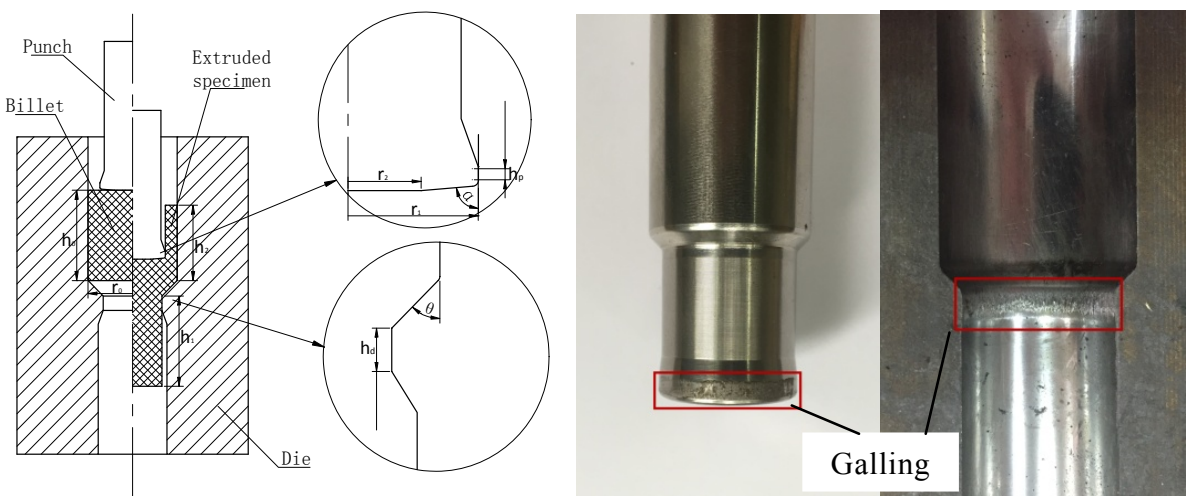

Fig. 3 Galling on sizing lands. Reproduced with permission from Ref. [22], (c) Elsevier B.V. 2017. 


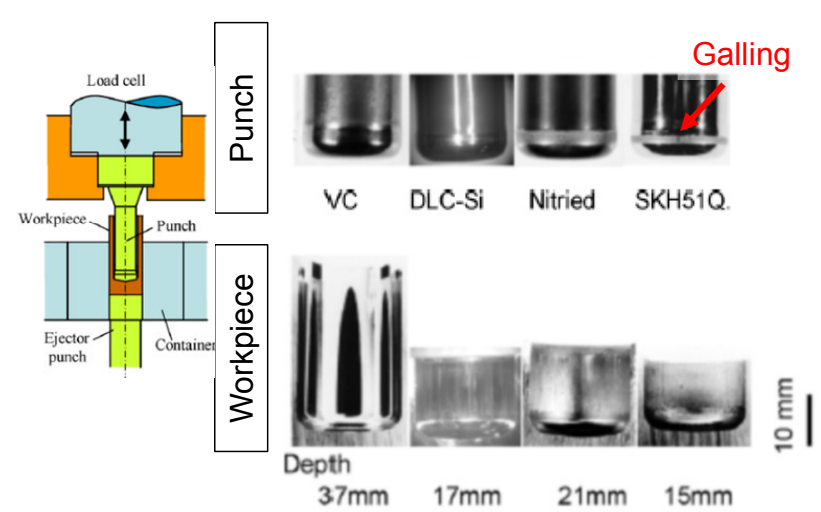

Fig. 4 Galling appearances in backward extrusion. Reproduced with permission from Ref. [23], (C) Elsevier B.V. 2012.

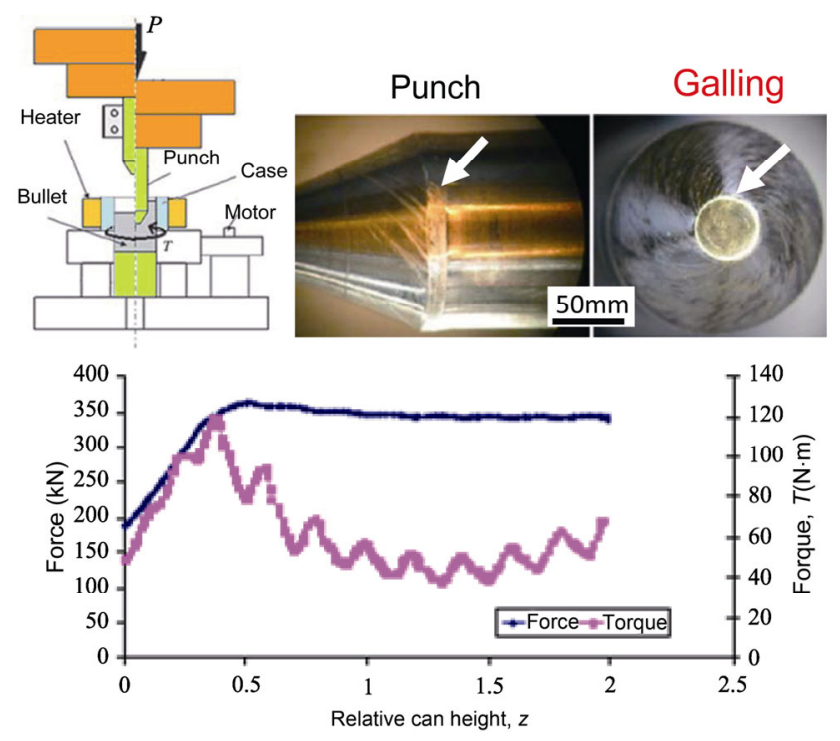

Fig. 5 Galling and friction behavior in rotational and backward extrusion. Reproduced with permission from Ref. [24], (C) Elsevier B.V. 2012.

blasted with S390 abrasive shots were used; immediate adhesion of the plates was observed during the first test [25].

At elevated temperatures, the galling phenomena are even more complex, especially in bulk-forming. The mechanisms of the degradation of hot forging tools are complex, as abrasive wear, oxidization, thermomechanical fatigue, and plastic deformation occur simultaneously and interact with each other [26]. Abrasive wear probably starts with adhesion. The mechanisms resulting in the transfer of aluminum on hot forming tools have been investigated from the standpoint of chemical and metallurgical interactions between the surfaces and mechanical interactions related to surface finish. Adhesion patches grew by adding more aluminum to the material already transferred in previous cycles [27]. In the warm and hot upsetting sliding tests, the contactor surface was heated to $200{ }^{\circ} \mathrm{C}$ by an embedded heating cartridge, whereas specimens made of AISI 4820 steel with a diameter of $30 \mathrm{~mm}$ were heated to $1,200{ }^{\circ} \mathrm{C}$ in an induction furnace and cooled down in the air to $1,100{ }^{\circ} \mathrm{C}$. The adhesion of the contactor (Fig. 6) could be observed with different degrees of deformation of the specimens after a test in which lubricant was not applied [28].

\subsection{Evolution of galling phenomena}

Figure 7 shows the basic idea of the evolution of galling phenomena in metal forming. Many factors contribute to galling. In different metal forming processes, the controlling factors are quite different, and their relationships are very complex. Considering the phenomena at the point where galling occurs at the tool-workpiece interface, initiation of galling occurs as a result of direct contact. This state can be understood by the destruction of the following three layers: (1) appearance of a surface being generated simultaneously with the destruction of the oxide film due to enlargement of the surface area of the workpiece, (2) breakage of the lubricant oil film due to a decrease in the kinematic viscosity caused by an increase in the interface temperature, and (3) the breakage of the thin hard coating of the tool's surface layer. This phenomenon is derived from the thermal stresses on the tool surface. An understanding of the above three factors is important in devising measures to prevent galling. Depending on the number of machining cycles, the frictional state changes as a result of a micro-gallin phenomenon. This point is often considered in modeling as a slip distance related to the number of cycles. The PV value is also important in the field of tribology, but the PV value is insufficient to represent the lubrication condition on the surface. Information on the local surface temperature (or heat) of the tool is as important as information on the local surface under boundary lubrication conditions.

\subsection{Effects of temperature on galling}

Galling is affected by the frictional surface temperature. 
Controlling the temperature in systems is essential since friction depends on the interface temperature [29]. The interface temperature is affected by the heat due to friction, heat due to plastic deformation, and the heat of the workpiece. Theoretically, the generated heat at the interface can be estimated through the flash temperature theory based on the assumption of the real contact area ratio and uniform interface [30-32]. Experimentally, the interface temperature distribution in metal forming is difficult to measure due to its severe condition. As it is not possible to install a temperature sensor near the contact surface, thermocouples are placed as close to the interface as possible. In practice, a method is adopted in which sensor holes and grooves are machined to install the thermocouples on the backside of the tool. The hole is made as small as possible so as not to affect the strength of the tool and heat transfer. Following embedding of the thermocouples, the temperature evolution (Fig. 8(a)) on the punch in extrusion [33], variation in temperature on the side of a forging die as a function of forging speed (Fig. 8(b)) [34], and temperature distribution of the roll [35] were obtained. The detected temperature

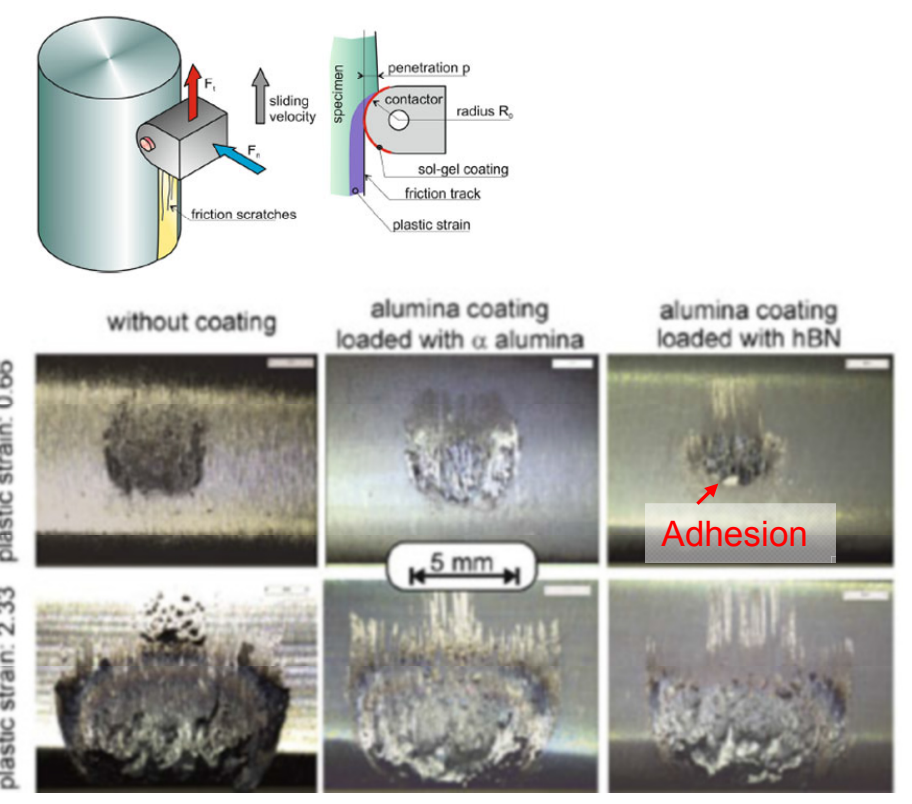

Fig. 6 Adhesion of material on the tool in warm penetration tests. Reproduced with permission from Ref. [28], (C Elsevier B.V. 2018 .

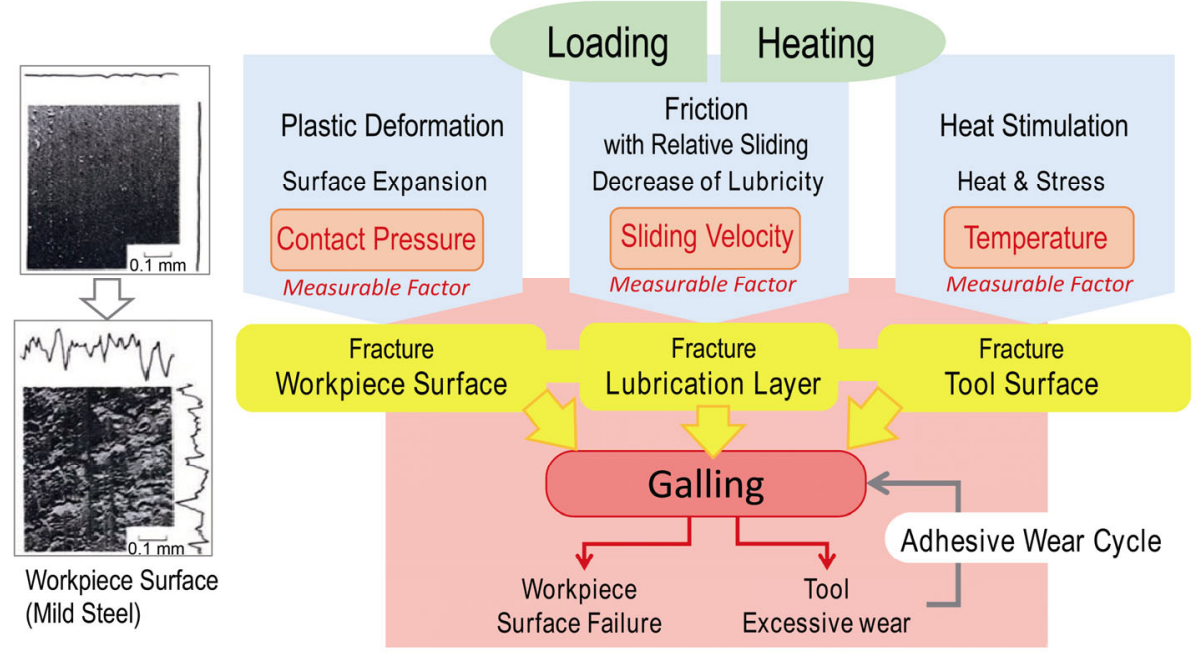

Fig. 7 Galling process during metal forming. 
(a) Punch
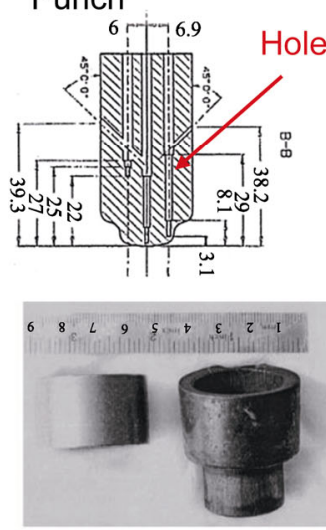

Formed shape

\section{es for thermocouple}

(b)
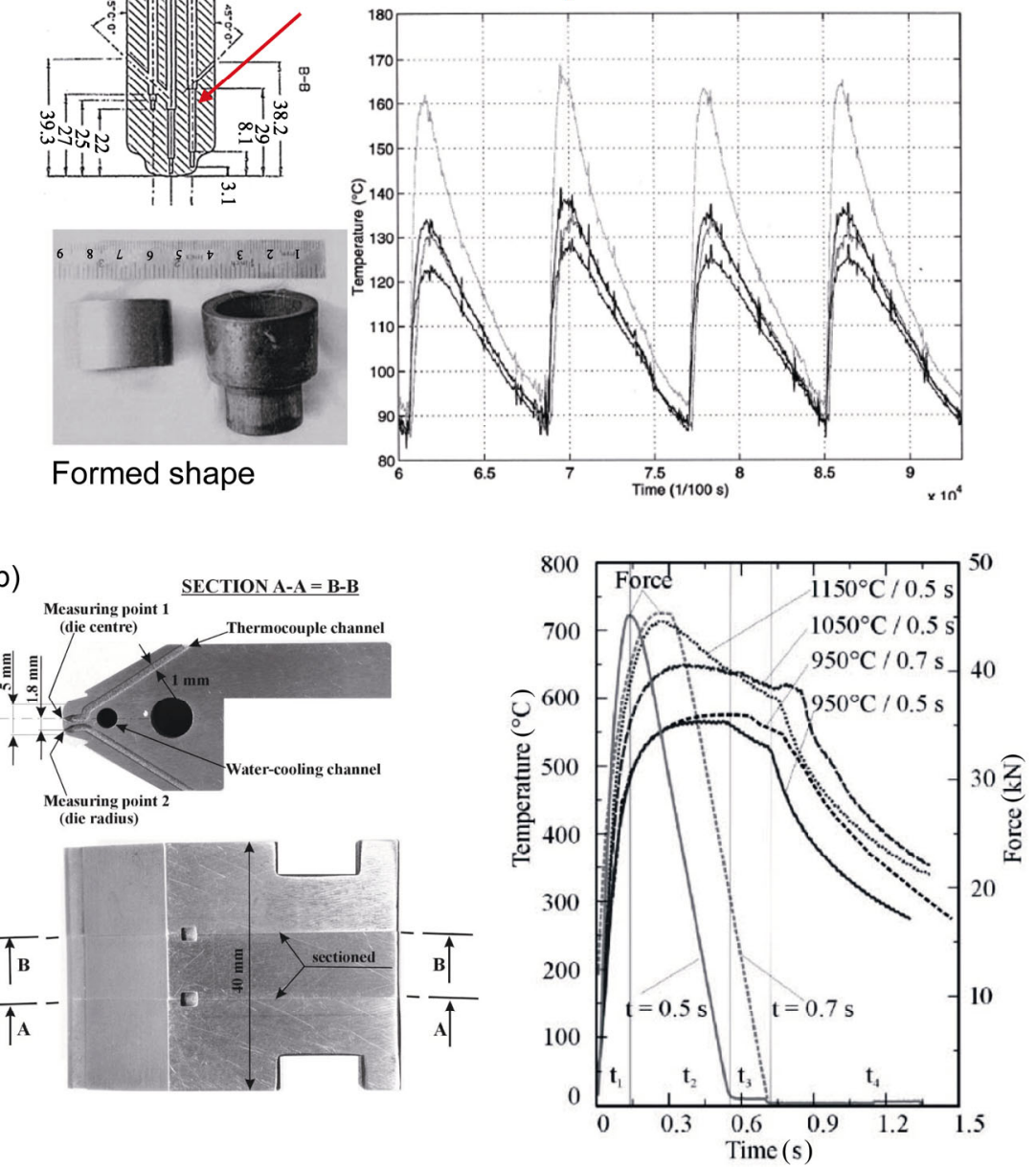

Fig. 8 Temperature measurement with thermocouples. (a) In extrusion punch. Reproduced with permission from Ref. [33], (C) Elsevier Science S.A. 1999. (b) In side forging die. Reproduced with permission from Ref. [34], (O Elsevier Science Ltd. 2002.

change depends on the distance from the interface to the thermocouple and the heat capacity.

The adhesion force is measured through a burnishing process under elevated temperatures [36]. Measurements show that the adhesion force is strengthened at elevated temperatures around $700{ }^{\circ} \mathrm{C}$ and that the temperature of the contact surface is roughly half the melting point of the material. The adhesion force increases with temperature rise, sliding speed, and diffusion progression. The relation between galling and interface temperature is investigated by different friction testing methods such as the strip reduction test (Fig. 9(a)) and twist compression test (Fig. 9(b)) with relatively little plastic deformation. The measured temperature distribution and the values obtained from finite element analysis are in good agreement $[37,38]$. To obtain a precise simulation result, it is necessary to measure the heat transfer coefficient between the tool and the workpiece.

\section{Anti-galling methods}

As mentioned above, the destruction of the protective film leads to galling. Therefore, galling can be preventing or delaying the destruction of the film. Although it is true that galling in metal forming should be avoided depending on the die design, in the case where process conditions closer to the critical state must be adopted in the design, a method that expands this critical condition is implied by the galling mechanism. In this section, various approaches for preventing galling and wear during 
(a)
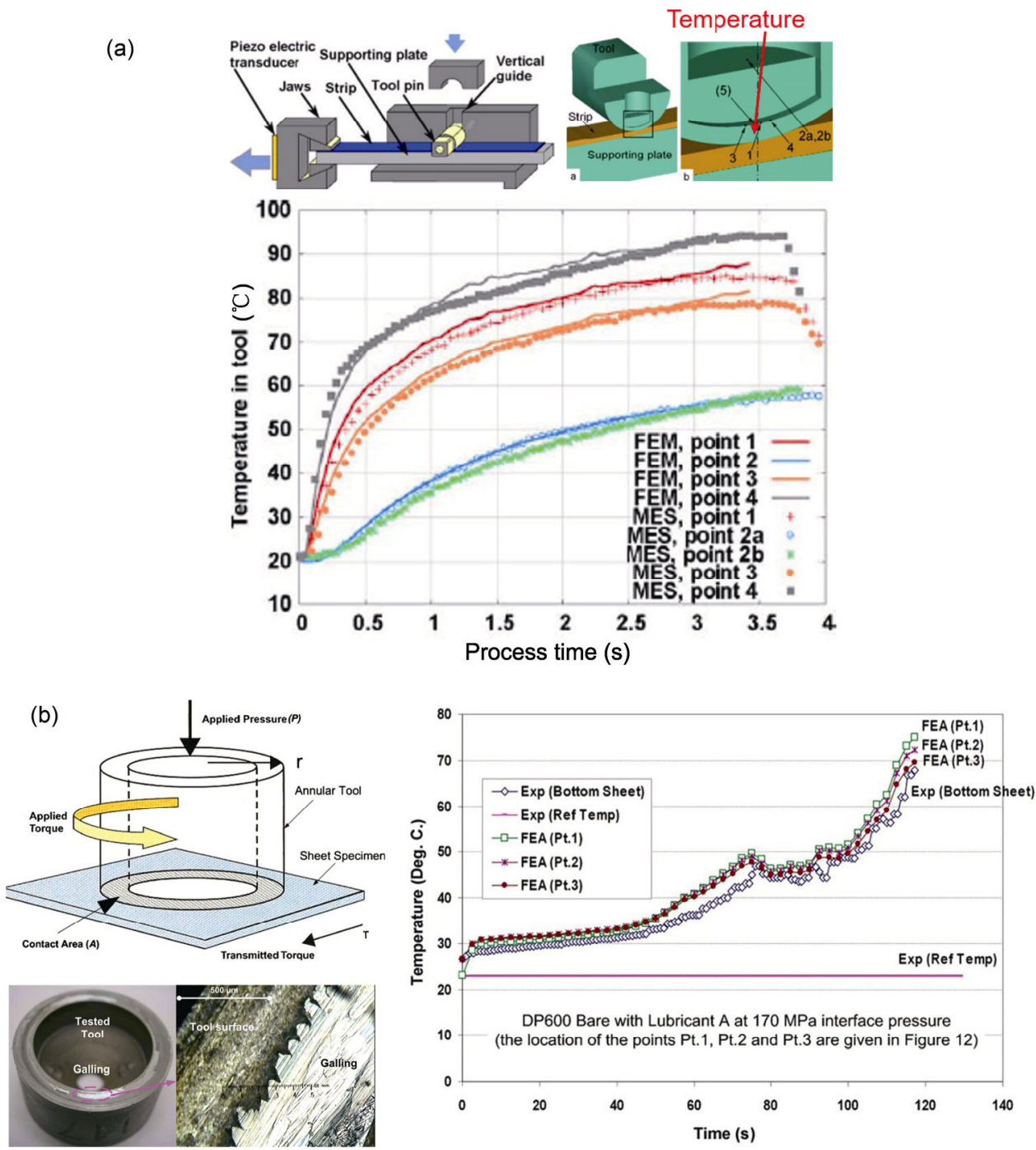

Fig. 9 Temperature evolution from measured and simulated results. (a) In strip reduction test. Reproduced with permission from Ref. [37], (c) CIRP. Published by Elsevier Ltd. 2004. (b) In twist compression test. Reproduced with permission from Ref. [38], (C) Elsevier B.V. 2007.

metal forming will be introduced.

\subsection{Improvement of lubricant performance}

The role of the lubricating film in metal forming is frictional force reduction and tool release. It is important to keep sufficient amounts of lubricant at the interface from the beginning to the end of processing; however, it is generally known that kinematic viscosity rapidly decreases with increasing temperatures and decreasing film thickness [39].

As an example, the local tool temperature in forging, could reach up to $600{ }^{\circ} \mathrm{C}$ [40]. The first principle of galling prevention is that the lubricants maintain the desired film thickness at elevated temperatures. Therefore, it is essential to raise their critical temperature by extreme pressure additives [41, 42]. In hot forging, their function is slightly different from that of ordinary lubricants, and the purpose is to facilitate the tool releasing and tool cooling processes. Graphite and white lubricants are mainly used in this process. Attention is also being paid to solid lubricants suitable for hightemperature forming [43] (Fig. 10). A study [44] to improve formability by controlling the heat transfer by the choice of the lubricant (Fig. 11) is also being conducted. From environmental-free, some examples of lubrication with organic oils have been tried and recently reported [45]. 


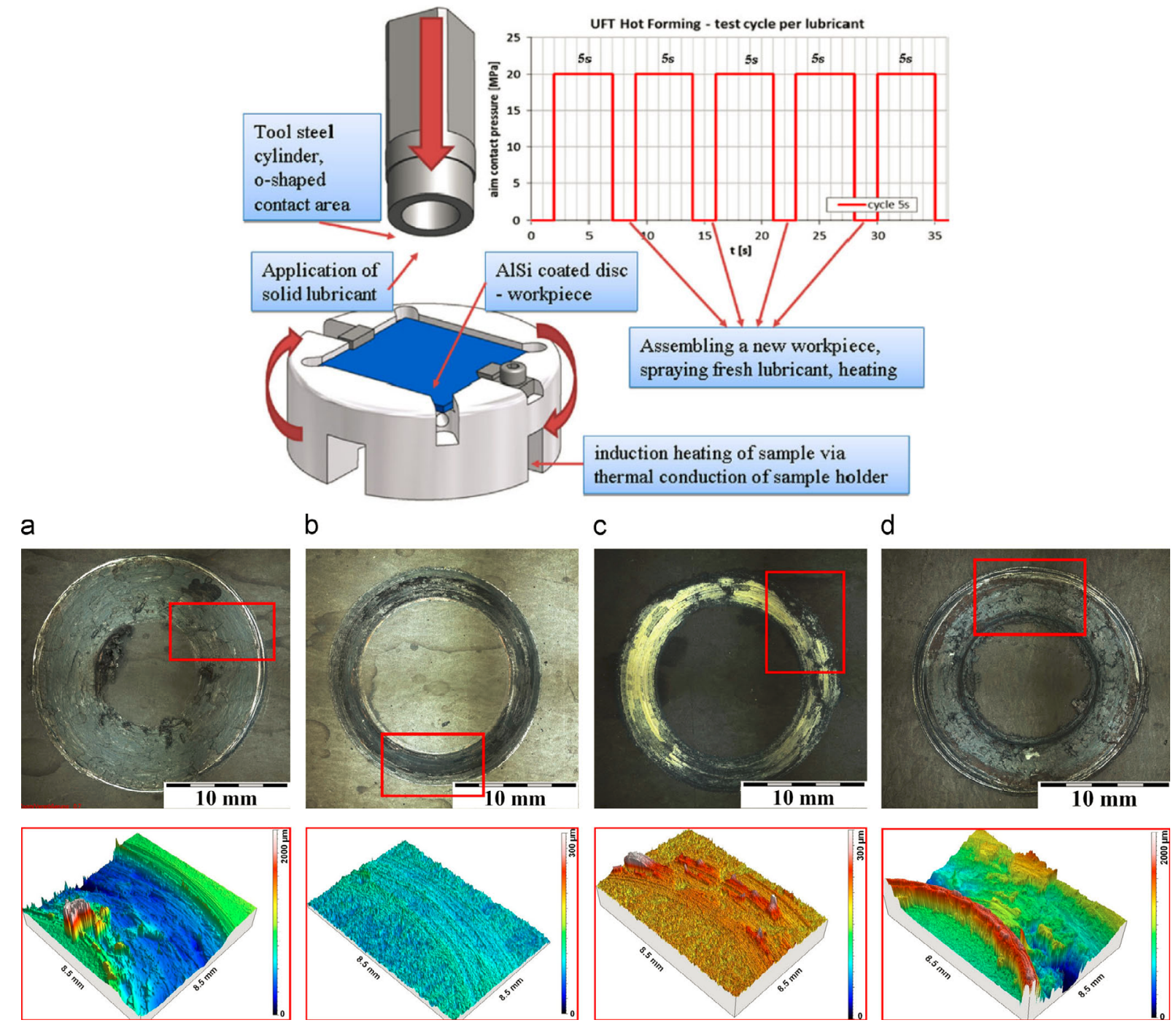

Fig. 10 Lubricant evaluation at elevated temperatures. Reproduced with permission from Ref. [43], C) Elsevier Ltd. 2014.
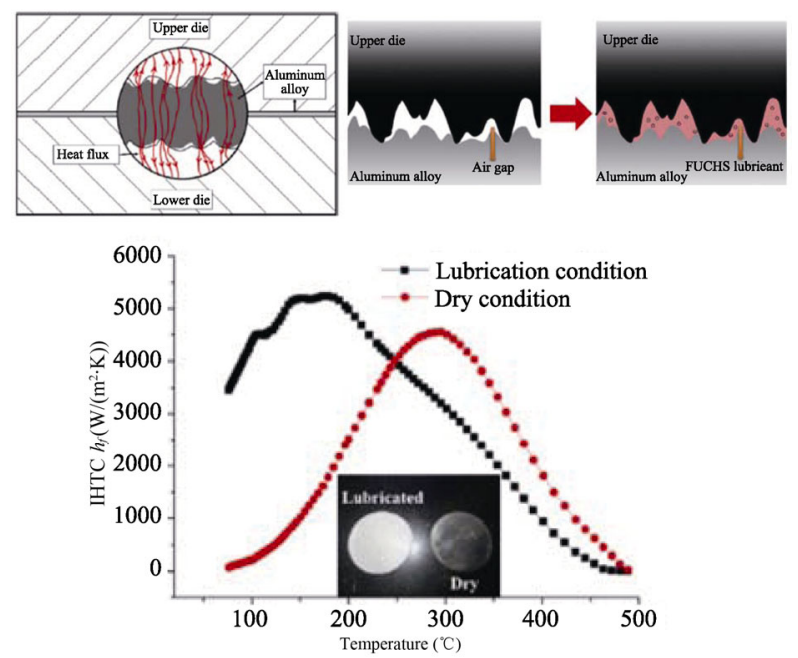

Fig. 11 Improvement of formability of AA7075 in sheet forming. Reproduced with permission from Ref. [44], (C) Elsevier Ltd. 2017.

\subsection{Improvement of anti-galling by coating the workpiece}

In cold forging, chemical conversion coatings composed of soap and phosphate are generally used to maintain a protective film under contact pressures as high as 3,000 $\mathrm{MPa}$ [46]. The improvement in galling resistance by phosphoric acid coatings is studied in detail in Ref. [47]. Researchers are also looking for alternative methods that are more eco-friendly from the viewpoint of industrial wastewater treatment related to conversion coating treatment [48]. A method for creating a new lubricating film for forging, which is used to replace the phosphate plus soap coating, has been proposed, and its galling 
properties have been noted [49].

In forming HSS sheets, Al-Si coatings have been applied to the workpiece, and galling properties were investigated in Ref. [50]. Furthermore, for galvanized HSS sheets, products specialized for enhancing galling resistance have been released [51]. Parts formed from Al-Si coated blanks exhibited lower mass loss but more aggressive wear behavior through adhesive wear of the die, while the workpiece related mass loss was higher for $\mathrm{Zn}-\mathrm{Ni}$. In the latter case, however, considerable metallic build-up layers on the die did not occur [52].

\subsection{Improvement of anti-galling by coated tools}

An effective means for reducing galling in metal forming is smoothing of the tool surface and bringing the contact surface closer to the fluid lubrication state. For smoothing, to minimize the level of irregularities, polishing is used as in the past, but there are economic restrictions. Coating is a surface modification method capable of stabilizing the boundary lubrication condition during processing by smoothing the surface and strengthening the vicinity of the tool surface.

Two physical vapor deposition (PVD) processes to make $\mathrm{Cr}$ and nitride layers on the surface, namely electron beam PVD (EBPVD) and unbalanced magnetron sputtering (UMS), have been investigated. The galling wear resistance of coatings deposited by UMS is approximately ten times that of the EBPVD coatings (Fig. 12), and the crystal orientation of the chromium coatings appears to play a significant role [53]. In cold sheet metal stamping, a PVD treatment of $\mathrm{CrN}$ on the D53 mold surface enhances the hardness to $1,600 \mathrm{HV}$, and the obtained good anti-adhesive properties of the surface significantly improve its galling resistance [54], as shown in Fig. 13. In hot aluminum forming, a hexagonal boron nitride (h-BN) coating has been used to improve the anti-galling property of the tool. Results from load-scanner tests at an elevated temperature of $400{ }^{\circ} \mathrm{C}$ reveal that large h-BN powder size and low h-BN concentration can help [55]. Ti-Al-N coatings with Ta have proven to enhance hardness, thermal stability, and oxidation resistance; however, by optimizing the chemical composition of $x$ alloyed $\mathrm{Ti}_{1-x} \mathrm{Al}_{x} \mathrm{~N}$ coatings, the oxidation resistance can be significantly improved, resulting in a much wider range of applications [56].

\subsection{Improvement of die materials}

By changing the chemical composition of tool steel, a new cold working tool steel with excellent capability in terms of galling resistance was developed [57]. The anti-galling properties were evaluated by using different grades of HSS sheets in the Hat-shaped bending test. The developed tool steel was superior to the conventional SKD 61, as shown in Fig. 14. Failed large hot forging dies were refabricated through a bimetal-layer weld surfacing technology
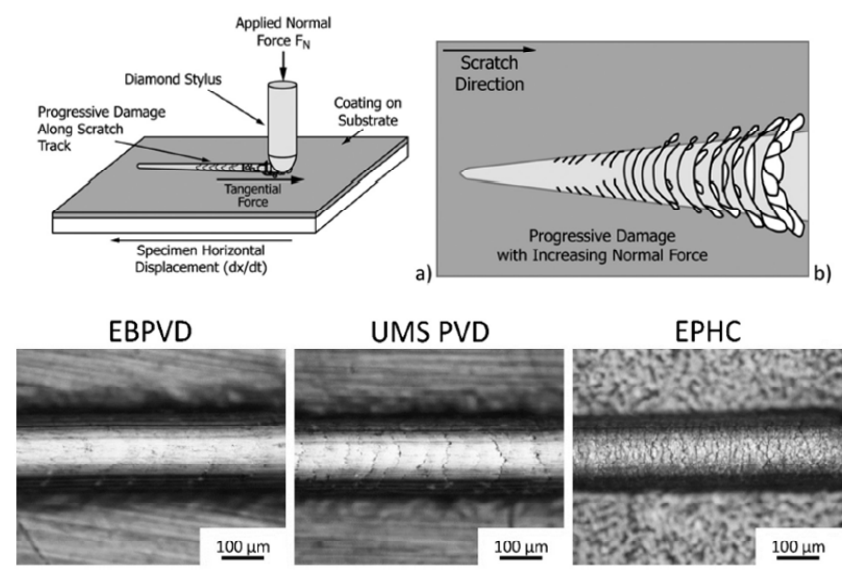

Fig. 12 Coating evaluation in scratch testing. Reproduced with permission from Ref. [53], C) Elsevier B.V. 2018.
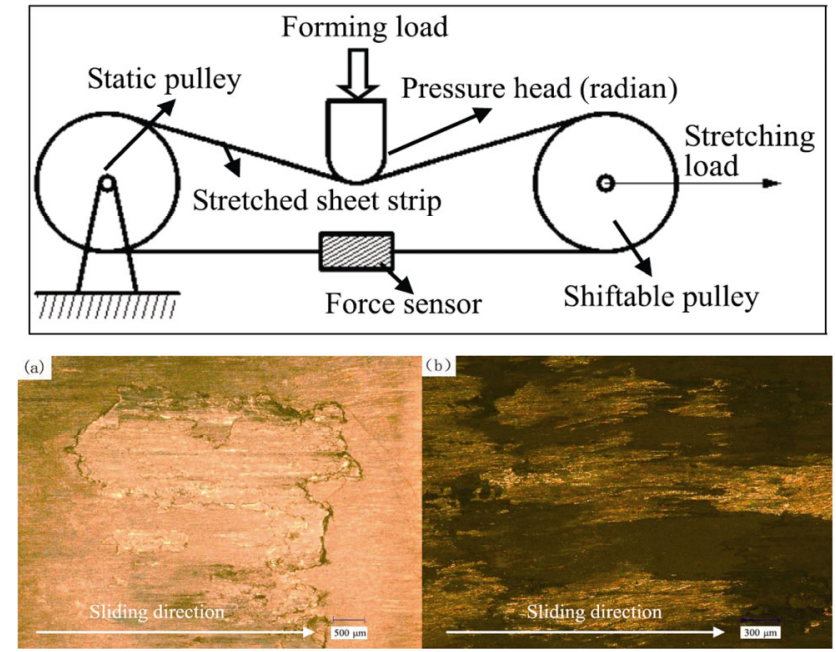

Fig. 13 Surface morphology after sliding of DC53 mold. (a) Quenched and tempered and (b) CrN coated. Reproduced with permission from Ref. [54], (C) Taylor \& Francis 2018. 


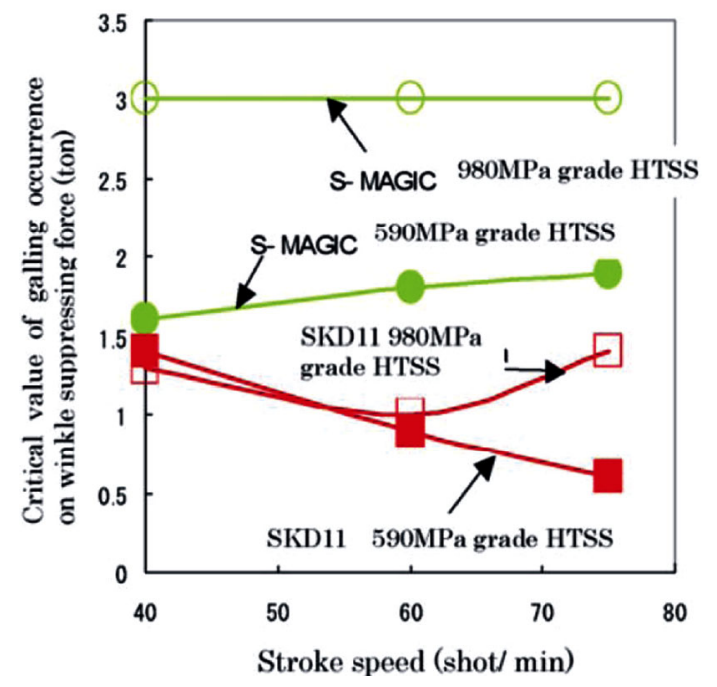

Fig. 14 Anti-galling tool steel for sheet forming. Reproduced with permission from Ref. [57], C) Elsevier B.V. 2011.

with a cobalt-based superalloy and a ferrous alloy. A hot working die with a three-layer structure was made of $5 \mathrm{CrNiMo}, \mathrm{Co} 03$, and JXHC15, as shown in Fig. 15. No failure was observed on the forging die after producing 25 pieces, and the feasibility of the die with a three-layer structure was verified [58].

\section{Measurement methods}

To understand the galling phenomena at the interface of tools in metal forming, it is essential to have a technique to quantitatively measure it at high resolution. An ASTM standard test method G98-02 exists, wherein a block specimen is generally kept stationary while a cylindrical button specimen loaded with a constant force is rotated during testing, and the threshold galling stress is evaluated [59]. A new parameter, the Galling 50 value, that represents the stress value at which galling is expected to occur in $50 \%$ of the tested specimens has been presented to provide a statistically relevant measure of galling resistance [60]. The Galling 50 value has been adopted by the ASTM standard test method G196-08 [61]. According to the standard method, a galling tester that could work at room

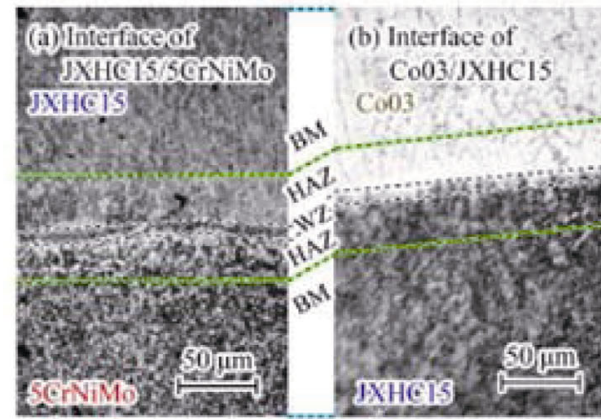

(a) Plastic deformation
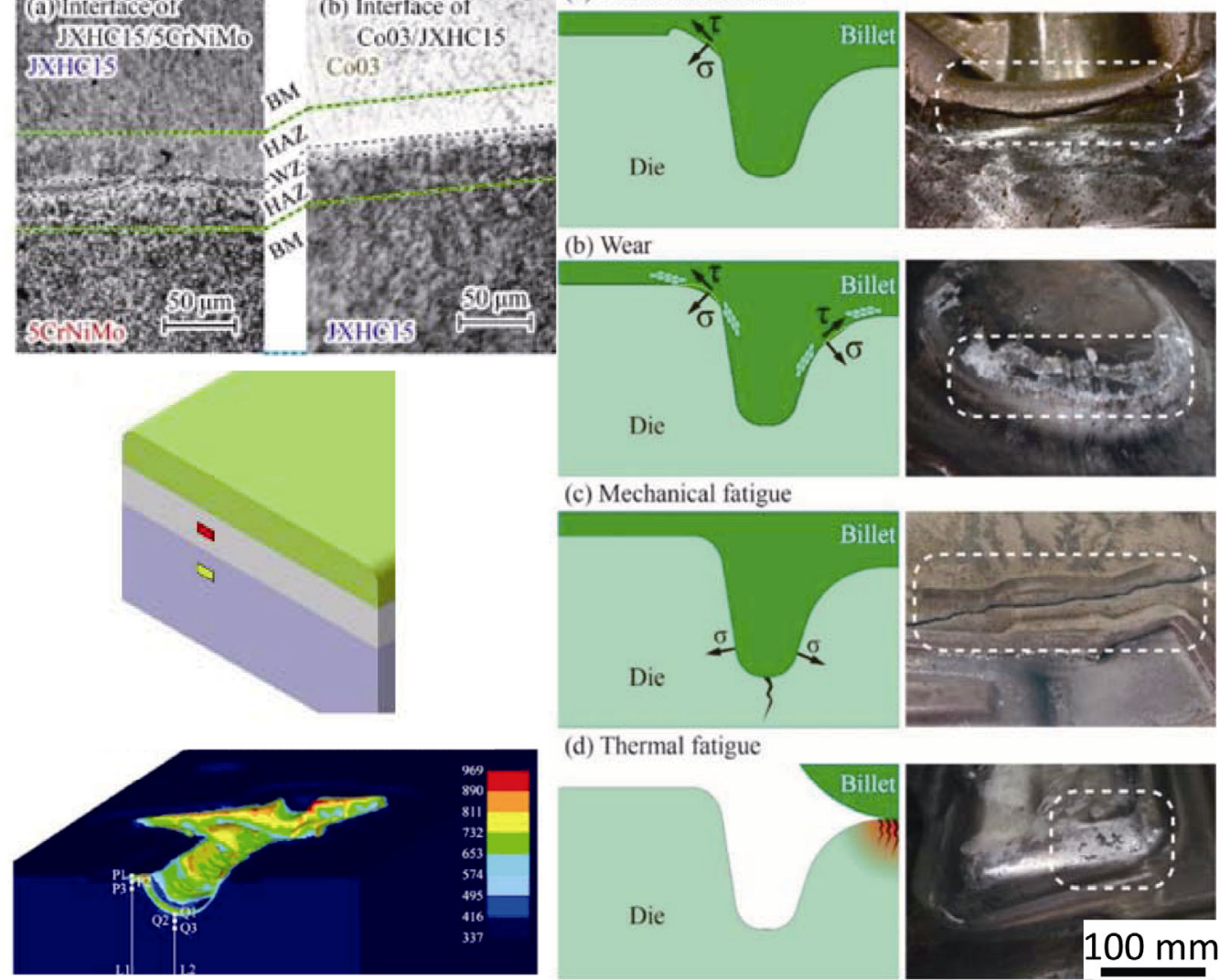

(d) Thermal fatigue

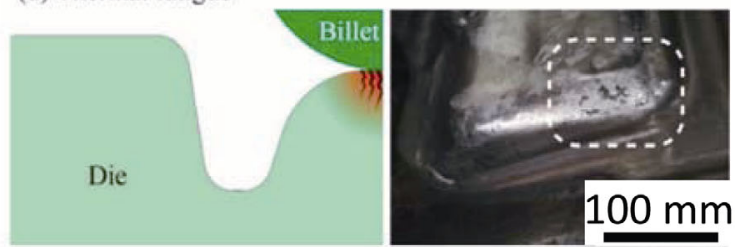

Fig. 15 Three-layer structure tool in hot forging. Reproduced with permission from Ref. [58], (C) The Society of Manufacturing Engineers. Published by Elsevier Ltd. 2018. 
and elevated temperatures of up to $300{ }^{\circ} \mathrm{C}$ has been developed [62].

As described in Section 2.4, the interface temperature is strongly related to the galling phenomena. Owing to the harshness of the tool interface in forging, it is quite difficult to capture the interface temperature. Due to the size of the sensor, the temperature distribution obtained is limited to discrete data [63]. Therefore, methods for detecting changes in surface properties during the forming process, the forming load profile of each shot, and the change in frictional force have been developed $[64,65]$. A sensoric fastener, which could gather the combined force and torque sensor signals in individual spatial directions, was invented to monitor pretensioning forces and operating loads in mechanical connections between components [66]. The method can be suitably applied to the monitoring of process and tool states in forging processes [67]. However, the force measurement is not an effective index for assessing galling because variations in the load are mostly hidden in changes in material properties, formed shapes, lubricating conditions, and other issues. To realize online monitoring of galling in metal forming processes, a correlation of the acoustic emission signal parameters to the severity of galling was found, and an attempt was made to use the acoustic emission measuring technique to inspect galling on sheet surfaces [68]. A novel wear sensor, which is printed conformal to the surface of or embedded into a material to detect the depth of abrasion, can be additively manufactured using direct writing methods for in-situ monitoring of wear and abrasion of materials [69].

\section{$5 \quad$ Galling prediction modeling}

To understand the galling phenomena, simulation tools such as the finite element method can be employed. In addition, three groups of models, wear progression models, relation models with friction laws, and galling growth models, can be applied along with the galling prediction methods described in the sections that follow.

\subsection{Friction models and galling}

Seizures could be described by boundary lubrication friction concepts [70, 71]. The frictional force is reduced in order to smoothly maintain the surface properties of the tool and the workpiece, and to allow for constant maintenance of the lubricating film during metal forming. In forming, as a result of plastic deformation, sliding of a newly born surface occurs, so the description scheme of the transition state is a major task of friction modeling [72]. As shown in Fig. 16, the local friction distribution affects deformation [73]. A friction model suitable for metal forming is desired.

A friction model was established as a function of normal pressure and interface temperature at the tool/workpiece interface and verified in a cold forward extrusion process performed at different reduction degrees [74]. A new friction law in cold dry forming, a constant friction coefficient at low contact pressure (Fig. 17(a)) and an associated frictional stress at high contact pressures were proposed and confirmed [75]. Another friction model that can distinguish between stress states at low and high contact pressures has been proposed. In the model,

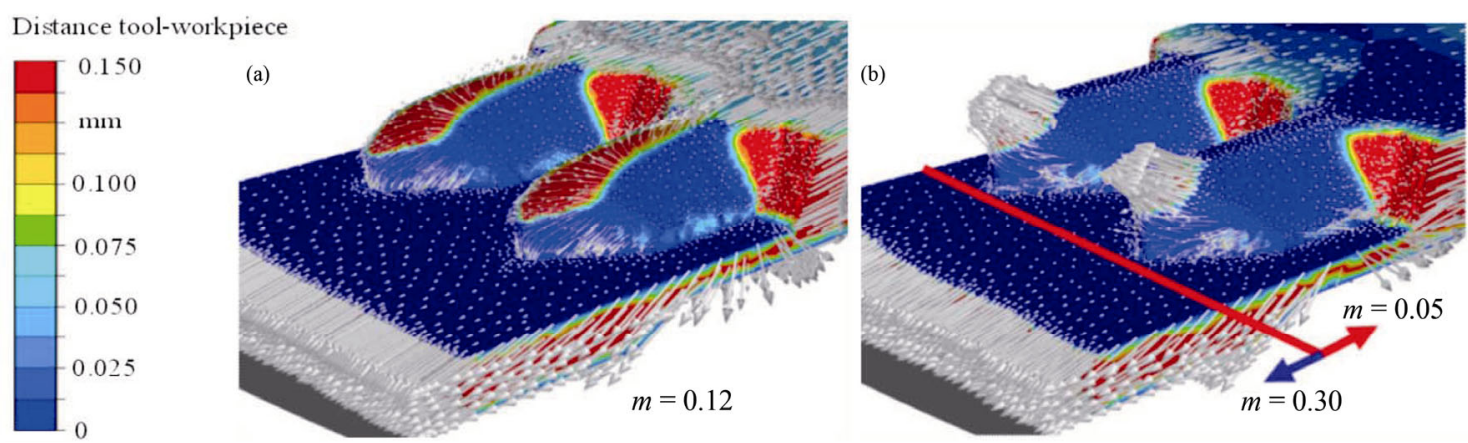

Fig. 16 Influence of frictional distribution on plastic deformation. Reproduced with permission from Ref. [73], (C) Elsevier Ltd. 2011. 
(a)
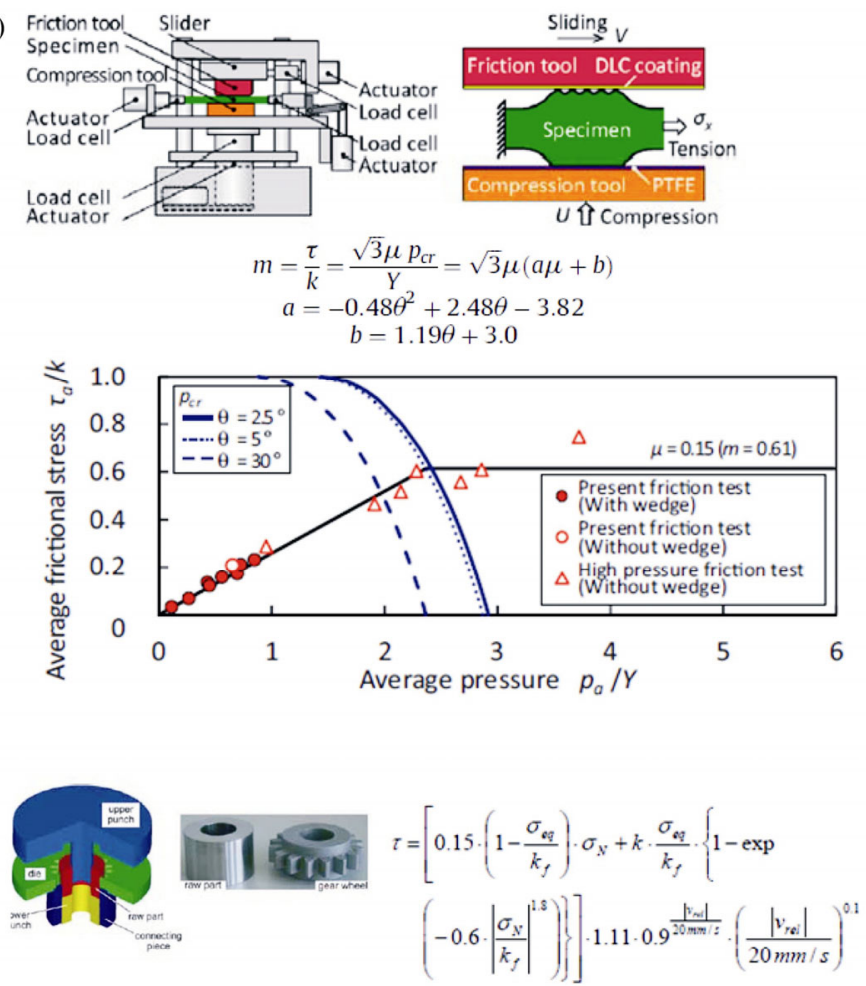

(b)

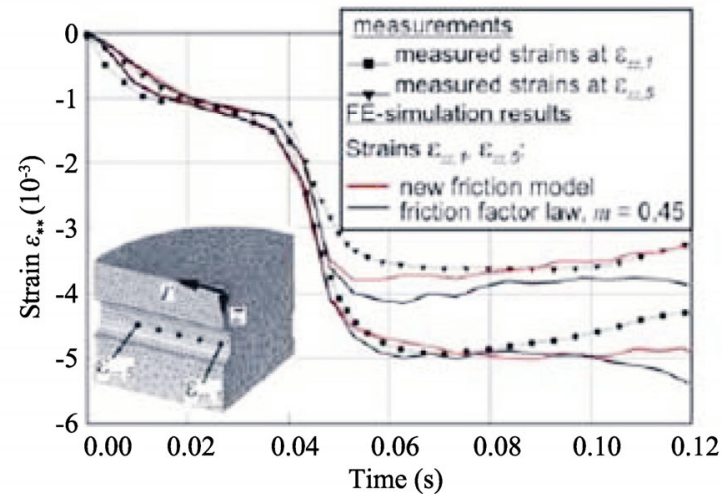

Fig. 17 Friction model for metal forming. (a) Relating to pressure and surface condition. Reproduced with permission from Ref. [75], (C) CIRP. Published by Elsevier Ltd. 2014. (b) Relating to slip rate and heat transfer. Reproduced with permission from Ref. [76], (C) Elsevier B.V. 2004.

the sliding velocity, equivalent stress, and yield stress were considered, as shown in Fig. 17(b) [76]. An empirically-based friction model describes friction as a function of the sliding distance and the most relevant friction influencing parameters [77]. In general, to create the friction model, parameters related to galling are always introduced.

\subsection{Wear models and galling}

Galling and wear, although different, are closely related, and minute changes in the frictional condition appear as wear on the tool as a result of repeated processes. Therefore, it is considered that a change in the friction condition of a surface is due to an accumulated micro seizure condition in each process. Under process conditions that simulate wear phenomena, surface condition is always observed as a form of wear progression rather than one of severe galling. The concept of adhesion friction and wear [78], and a delamination theory based on fracture mechanics [79] have been theoretically established. During cycles of adhesion wear, the 
detachment of agglomerates is considered a major cause of wear; once adhered fine particles peel off, they scratch the surface layer again. In this cycle, the adhesion wear grows until it appears as galling [80]. In the case of adhesion wear, the total sliding distance is relatively long. Experimentally, this phenomenon can be easily observed in the testing processes of the rolling or drawing type [81].

Archard and Hirst [82] and Oyane [83] proposed wear models that can be applied in FEM analysis. They are based on the concept of plastic working at the interface. It is assumed that the progress of wear is on a wear-plastic working curve, which is gain the above theories. Simulations that take into consideration changes in the tool shape due to wear have been conducted [84]. A simulation example for a case in which a newly designed tool is simulated by considering the galling height has been performed [85].

\subsection{Galling growth model}

Based on a model focusing on the adhesion phenomenon, a galling growth model has been proposed [86]. As shown in Eq. (1), the galling increment is described by the following factors: contact pressure, surface area expansion, equivalent thermal conductivity, temperature, and sliding increment.

$$
\begin{gathered}
\mathrm{d} s=f(P, \eta)(1-s) K \times \exp (-\alpha / T) \mathrm{d} L \\
f(P, \eta)=\left\{\begin{array}{c}
0\left(\frac{P}{\sigma_{Y}}>1\right) \\
\frac{P}{\sigma_{Y}} \times \frac{\eta-1}{\eta}\left(\frac{P}{\sigma_{Y}} \leqslant 1\right)
\end{array}\right.
\end{gathered}
$$

where $s$ is the adhesion area degree, $\mathrm{d} s$ is the adhesion area increment, $\eta$ is the surface area expansion ratio, $P$ is the contact surface pressure, $\mathrm{d} L$ is the slip distance increment, $K$ and $\alpha$ coefficients are determined by a combination of tool and workpiece materials, and $\sigma_{Y}$ is the yield stress. The $s$ indicates the degree of adhesion in the examination area, $A$. Assuming that the inspection area is $A$, the seizure area degree can be calculated by $A^{\prime} / A . \mathrm{d} s$ is the increment in time unit. The resultant area $A^{\prime \prime}$, which changes over time, is calculated from $A^{\prime \prime} / A$.
From the results given in Fig. 18, the predicted results agree with the experimental results at small slip distances, but deviate at long distances. This is because adhesion growth in three dimensions has not been modeled. Furthermore, the prediction model could be improved for mechanisms involving heat generation, as it does not take into account the local temperature increase by heat generated through deformation and friction.

\section{Galling in other processes}

In this section, rather than being limited to metal forming, it may be possible to find useful information on other manufacturing processes to help to understand galling phenomena. The phenomena at the interface at the constituent cutting edge in cutting and friction stir welding (FSW) are similar to those in metal forming. The galling phenomena that occur during other processes are different from the galling phenomena observed in metal forming, however, the phenomena share a common mechanism.

To understand the mechanism underlying microscopic initiation of galling, it is very important to make clear the effects of temperature. The related observed methods, such as local temperature measurement in different processes could contribute to the study of the mechanisms of galling phenomena.

\subsection{Cutting}

Build-up edges in cutting processes [87] exhibit a behavior that is similar to the galling phenomena in metal forming. In the cutting process, especially that of an aluminum alloy, to understand build-up edge phenomena occurring under certain conditions, the interface temperature is measured by a thermocouple to estimate the heat transfer state between the workpiece and tool [88]. In the cutting process, a group of thin-film thermocouples are arranged at the tip of the insert under the rake face to measure the tool-chip temperature distribution. The array of micro-thin film thermocouples is embedded into polycrystalline cubic boron nitride cutting inserts (Fig. 19) using diffusion bonding. Temperature 

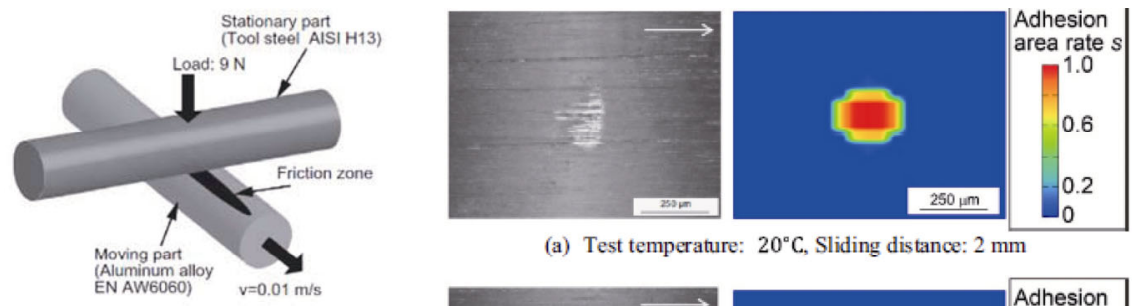

(a) Test temperature: $20^{\circ} \mathrm{C}$, Sliding distance: $2 \mathrm{~mm}$
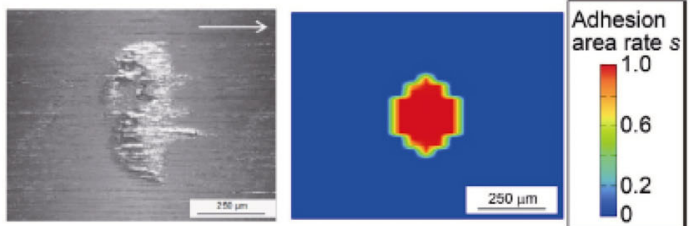

(b) Test temperature: $20^{\circ} \mathrm{C}$, Sliding distance: $68 \mathrm{~mm}$
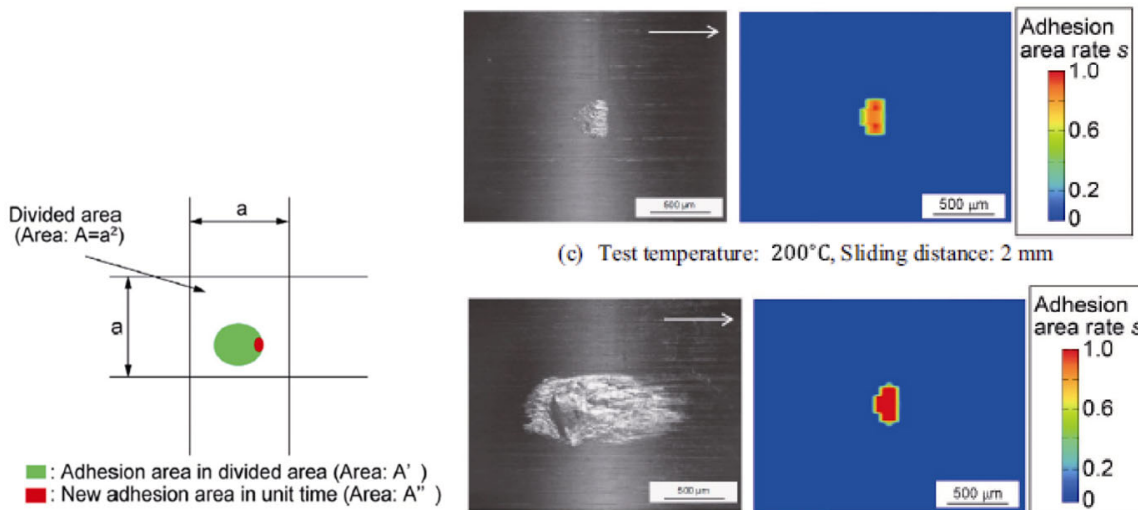

(c) Test temperature: $200^{\circ} \mathrm{C}$, Sliding distance: $2 \mathrm{~mm}$
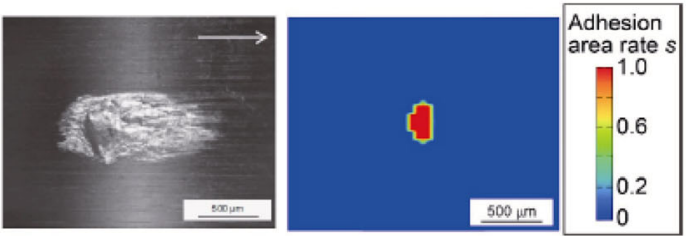

(d) Test temperature: $200^{\circ} \mathrm{C}$, Sliding distance: $68 \mathrm{~mm}$

Fig. 18 Galling growth model. Reproduced with permission from Ref. [86], (C Society of Manufacturing Engineers (SME). Published by Elsevier Ltd. 2018.

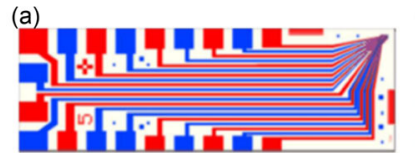

(b)

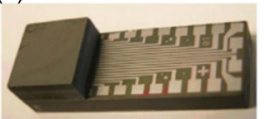

(c)

(d)

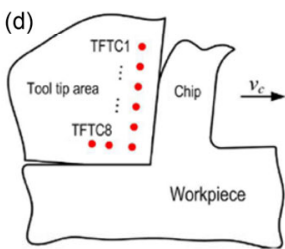

Unit mm

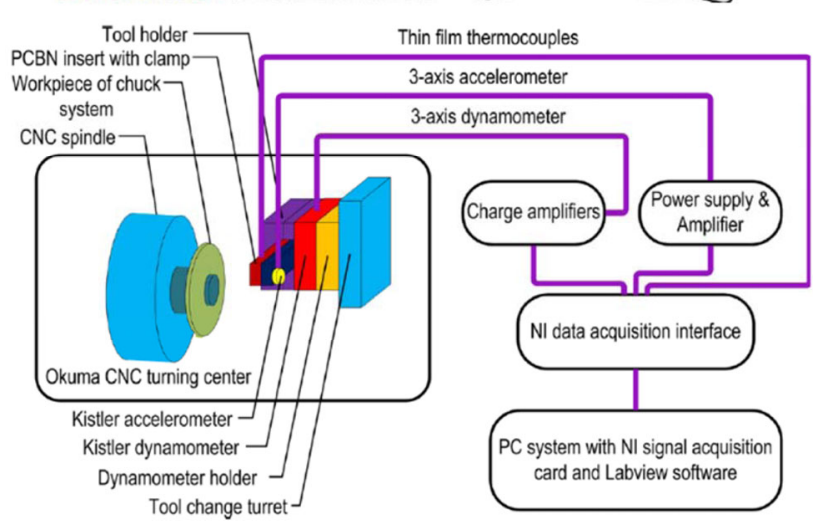

Fig. 19 Cutting. Reproduced with permission from Ref. [90], (C) Elsevier Ltd. 2013. data can be obtained quickly, accurately, and reliably during cutting $[89,90]$.

\subsection{Friction stir welding}

The joining process in FSW [91, 92] shows similar behavior as galling phenomena in metal forming. In the FSW process, the temperature and thermal stresses were investigated by the in-situ neutron diffraction method, where the deep penetration capability of neutrons made it possible, for the first time, to obtain data inside the workpiece [93]. Furthermore, a calculation method based on the molecular dynamics method can be used to understand the deformation and temperature phenomena of interfaces [94]. The corresponding finite element model is shown in Fig. 20. A real-time wireless temperature measurement system using a bluetooth module has been developed, where a tiny thermocouple was installed at the tip of the rotary tool, and used to successfully implement a closed-loop control of the interface temperature [95]. 

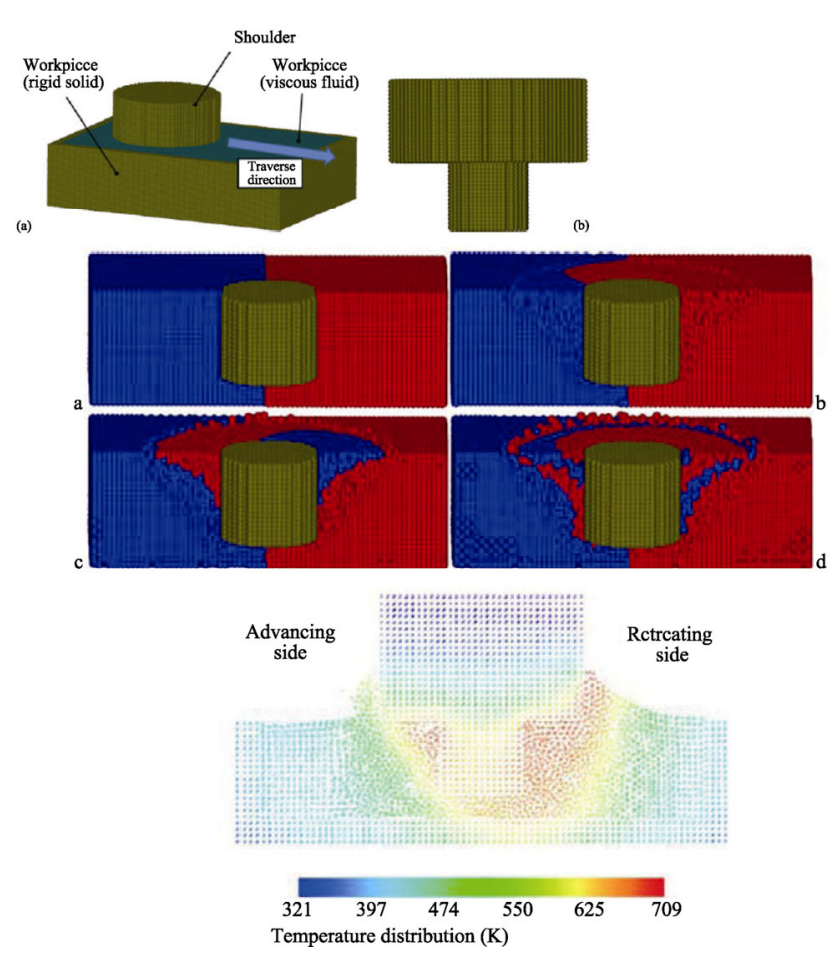

Fig. 20 Particle method in FSW. Reproduced with permission from Ref. [94], (C) Taylor \& Francis 2012.

The above developed interfacial temperature measurement technologies for other processes have the potential to be applied to tools in metal forming to detect the surface change due to galling. Although real galling phenomena are quite complex, molecular dynamics methods or another numerical simulation method could be used to model galling in metal forming in the next stage of research.

\section{Summary and concluding remarks}

1) Studies on galling in metal forming are reviewed. The actual conditions of galling are different in sheet metal and bulk metal forming processes. Typical galling defects are exemplified by deferent cases in sheet and bulk-forming to show the appearance of galling in metal forming. Furthermore, the evolution of galling is explained in three phases. Among the main impact parameters, the effect of temperature on galling is emphatically discussed.

2) To prevent galling defects or delay their progress, different anti-galling methods such as improvement of the lubricant properties of the die materials, coating the workpiece, and using coated tools could be applied. The first principle of lubricant use in maintaining the desired film thickness at elevated temperatures. Tool steels with excellent capability in terms of galling resistance, pre-coated workpieces, and hard tool coatings are recommended. The new coating techniques show promise in improving the anti-galling characteristics in metal forming.

3) Quantitative measurement technologies with high resolution need to be developed. Indirect evaluation indexes such as specific stress, frictional force, and forming load are being used, but the variation in these values is mostly buried in changes due to many factors. Attempts have been made to use in-situ monitoring methods to monitor galling processes. In the future, online monitoring techniques could be an important research field.

4) With the development of friction and wear models, friction behavior and wear progress could be simulated, and galling phenomena could be better understood. A galling growth model has been proposed, but adhesion growth in 3D has not been modeled. A prediction model that considers the local heat causing deformation and friction is needed to create improved galling models related to heat.

5) Interfacial temperature measurement techniques are quite important for understanding galling phenomena. The galling phenomena in cutting and friction stir welding processes were also investigated. The related observed technologies that use an array of micro-thin film thermocouples and a real-time wireless temperature measurement system could contribute to the study of mechanisms in galling.

Open Access This article is licensed under a Creative Commons Attribution 4.0 International License, which permits use, sharing, adaptation, distribution and reproduction in any medium or format, as long as you give appropriate credit to the original author(s) and the source, provide a link to the Creative Commons licence, and indicate if changes were made.

The images or other third party material in this 
article are included in the article's Creative Commons licence, unless indicated otherwise in a credit line to the material. If material is not included in the article's Creative Commons licence and your intended use is not permitted by statutory regulation or exceeds the permitted use, you will need to obtain permission directly from the copyright holder.

To view a copy of this licence, visit http://creativecommons.org/licenses/by/4.0/.

\section{References}

[1] Rabinowicz E. Friction seizure and galling seizure. Wear 25(3): 357-363 (1973)

[2] Yoon J W, Barlat F. Modeling and simulation of the forming of aluminum sheet alloys. In ASM Handbook Volume 14B: Metalworking: Sheet Forming. Semiatin S L, Ed. Almere: ASM International, 2006: 257-258.

[3] NSK. New Bearing Doctor. 4th edn. Japan: NSK Ltd., 2014: 28 .

[4] Leao J D, Bouillon V, Muntada L, Johnson C, Wilson P, Vergnes O, Dano C, Igartua A, Mendoza G. New formulations of sunflower based bio-lubricants with high oleic acid content-VOSOLUB project. Ol Corps Gras Lipides, 23(5): D509 1-8 (2016)

[5] Wang Z. Galling behavior in square cup drawing of high-tensile-strength steel. J Jpn Soc Tech Plasticity, 55(640): 391-395 (2014)

[6] Schey J A. Tribology in metalworking: Friction, lubrication, and wear. J Appl Metalworking 3(2): 173173 (1984)

[7] Bhushan B. Introduction to Tribology. New York (USA): John Wiley \& Sons, 2002: 207-210.

[8] Schedin E. Galling mechanisms in sheet forming operations. Wear 179(1-2): 123-128 (1994)

[9] Ives L K, Peterson M B, Whitenton E P. The mechanism, measurement, and influence of properties on the galling of metals. NISTIR 89-4064. Gaithersburg (USA): National Institute of Standards and Technology, 1989: 15.

[10] Wang Z G. Tribological issues for leading metal forming products cost reduction. J Jpn Soc Technol Plast 52(600): 113-115 (2011)

[11] Dohda K, Boher C, Rezai-Aria F, Mahayotsanun N. Tribology in metal forming at elevated temperatures. Friction 3(1): 1-27 (2015)

[12] Nakamura T. Measurement technique of tribology characteristics in metal forming. J Jpn Soc Technol
Plast 57(669): 955-959 (2016)

[13] Vižintin J, Kalin M, Dohda K, Jahanmir S. Tribology of Mechanical Systems: A Guide to Present and Future Technologies. New York (USA): American Society of Mechanical Engineers, 2004.

[14] Totten G E. ASM Handbook: Volume 18-Friction, Lubrication, and Wear Technology. Ohio (USA): ASM International, 2017: 808-816.

[15] Mozgovoy S, Hardell J, Deng L, Oldenburg M, Prakash B. Tribological behavior of tool steel under press hardening conditions using simulative tests. J Tribol 140(1): 011606 (2018)

[16] Godi A, Grønbæk J, De Chiffre L. Off-line testing of multifunctional surfaces for metal forming applications. CIRP J Manuf Sci Technol 11: 28-35 (2015)

[17] Wang W R, Zheng X K, Hua M, Wei X C. Influence of surface modification on galling resistance of DC53 tool steel against galvanized advanced high strength steel sheet. Wear 360-361: 1-13 (2016)

[18] Katagiri T. Effects of tool coatings on anti-galling property in forming of high strength steel. J Jpn Soc Technol Plast 48(562): 962-966 (2007)

[19] Nishino S, Ohya K. Damage evaluation of coatings for press forming die. J Jpn Soc Technol Plast 56(650): 176-180 (2015)

[20] Liu Y, Zhu Z J, Wang Z J, Zhu B, Wang Y L, Zhang Y S. Flow and friction behaviors of 6061 aluminum alloy at elevated temperatures and hot stamping of a B-pillar. Int J Adv Manuf Technol 96(9-12): 4063-4083 (2018)

[21] Venema J, Hazrati J, Matthews D T A, Stegeman R A, van den Boogaard A $\mathrm{H}$. The effects of temperature on friction and wear mechanisms during direct press hardening of Al-Si coated ultra-high strength steel. Wear 406-407: 149-155 (2018)

[22] Hu C L, Yin Q, Zhao Z. A novel method for determining friction in cold forging of complex parts using a steady combined forward and backward extrusion test. J Mater Process Technol 249: 57-66 (2017)

[23] Dohda K, Tsuchiya Y, Kitamura K, Mori H. Evaluation of tribo-characteristics of diamond-like-carbon containing Si by metal forming simulators. Wear 286-287: 84-91 (2012)

[24] Ceron E, Bay N, Aida T, Dohda K, Nicolaisen T E. Simulative testing of friction and lubrication in cold forging of steel and aluminum. In Proceedings of North American Manufacturing Research Conference, United States, 2012.

[25] Groche P, Müller C, Jahn A. Effects of the tool lubrication in cold forging. Tribol Lett 53(3): 599-605 
(2014)

[26] Gronostajski Z, Kaszuba M, Hawryluk M, Zwierzchowski M. A review of the degradation mechanisms of the hot forging tools. Arch Civ Mech Eng 14(4): 528-539 (2014)

[27] Pujante J, Vilaseca M, Casellas D, Riera M D. The role of adhesive forces and mechanical interaction on material transfer in hot forming of aluminium. Tribol Lett 59(1): 10 (2015)

[28] Dubois A, Dubar M, Debras C, Hermange K, Nivot C, Courtois C. New environmentally friendly coatings for hot forging tools. Surf Coat Technol 344: 342-352 (2018)

[29] Hardell J, Kassfeldt E, Prakash B. Friction and wear behaviour of high strength boron steel at elevated temperatures of up to $800{ }^{\circ} \mathrm{C}$. Wear 264(9-10): 788-799 (2008)

[30] Archard J F. The temperature of rubbing surfaces. Wear 2(6): 438-455 (1959)

[31] Ling F F, Saibel E. Thermal aspects of galling of dry metallic surfaces in sliding contact. Wear 1(2): 80-91 (1957)

[32] Blok H. The flash temperature concept. Wear 6(6): 483-494(1963)

[33] Brucelle O, Bernhart G. Methodology for service life increase of hot forging tools. J Mater Process Technol 87(1-3): 237-246 (1999)

[34] Terčelj M, Turk R, Knap M. Assessment of temperature on the die surface in laboratory hot metal forming. Appl Therm Eng 23(2): 113-125 (2003)

[35] Yoneyama T, Asaoka H, Kimura H, Hoshino I, Kokubo M. Heat transfer and roll surface temperature in the hot rolling of aluminum sheet. $J$ Tribol 121(4): 753-760 (1999)

[36] Iwata K, Aihara J, Kurasaka K. Adhesion of carbide and carbon steels at high pressures and temperatures. Trans Jpn Soc Mech Eng 38(309): 1098-1105 (1972)

[37] Olsson D D, Bay N. Andreasen J L. Prediction of limits of lubrication in strip reduction testing. CIRP Ann 53(1): 231-234 (2004)

[38] Kim H, Sung J, Goodwin F E, Altan T. Investigation of galling in forming galvanized advanced high strength steels (AHSSs) using the twist compression test (TCT). J Mater Process Technol 205(1-3): 459-468 (2008)

[39] Sethuramiah A, Okabe H, Sakurai T. Critical temperatures in EP lubrication. Wear 26(2): 187-206 (1973)

[40] Groche P, Müller C, Stahlmann J, Zang S. Mechanical conditions in bulk metal forming tribometers-Part one. Tribol Int 62: 223-231 (2013)
[41] Dohda K, Wang Z, Miwa K, Kashiwaya T. Lubricity of phosphorus EP additives in ironing process. Trans Jpn Soc Mech Eng, Ser C 66(649): 3143-3149 (2000)

[42] Chen Y, Wang X Z, Clearfield A, Liang H. Anti-galling effects of $\alpha$-zirconium phosphate nanoparticles as grease additives. J Tribol 141(3): 031801 (2019)

[43] Tomala A, Hernandez S, Ripoll M R, Badisch E, Prakash B. Tribological performance of some solid lubricants for hot forming through laboratory simulative tests. Tribol Int 74: 164-173 (2014)

[44] Ying L, Gao T H, Dai M H, Hu P. Investigation of interfacial heat transfer mechanism for 7075-T6 aluminum alloy in HFQ hot forming process. Appl Therm Eng 118: 266-282 (2017)

[45] Medea F, Ghiotti A, Bruschi S. Temperature effects on organic lubricants in cold forging of AA1050 alloy. Procedia Manuf 5: 308-318 (2016)

[46] Bay N. The state of the art in cold forging lubrication. $J$ Mater Process Technol 46(1-2): 19-40 (1994)

[47] Komiyama S, Wang Z G, Tokunaga R, Yamaoka Y. Effect of tool surface roughness on friction behavior of lubricant coating in cold forging. J Jpn Soc Technol Plast 51(591): 342-347 (2010)

[48] Bay N, Azushima A, Groche P, Ishibashi I, Merklein M, Morishita M, Nakamura T, Schmid S, Yoshida M. Environmentally benign tribo-systems for metal forming. CIRP Ann 59(2): 760-780 (2010)

[49] Yoshida M, Imai Y, Shimizu A, Komiyama S, Yamaguchi H, Ootake M, Wang Z G. Revolution of lubrication in cold forging by dry in-place type coating system "PULS". J Jpn Soc Technol Plast 55(647): 1058-1062 (2014)

[50] Pelcastre L, Hardell J, Rolland A, Prakash B. Influence of microstructural evolution of Al-Si coated UHSS on its tribological behaviour against tool steel at elevated temperatures. J Mater Process Technol 228: 117-124 (2016)

[51] JEF. JFE steel develops "GI JAZTM" high-lubricity GI steel sheet for automobiles. http://www.jfe-steel.co.jp/ en/release/2018/181115.html, 2018-12-13.

[52] Kondratiuk J, Kuhn P. Tribological investigation on friction and wear behaviour of coatings for hot sheet metal forming. Wear 270(11-12): 839-849 (2011)

[53] Daure J L, Carrington M J, Shipway P H, McCartney D G, Stewart D A. A comparison of the galling wear behaviour of PVD $\mathrm{Cr}$ and electroplated hard $\mathrm{Cr}$ thin films. Surf Coat Technol 350: 40-47 (2018)

[54] Zhou L H, Gao K X, Zheng X K, Wang W R, Wei X C, Hua M. Developing of galling during the forming and 
its improvement by physical vapour depositing. Surf Eng 34(7): 493-503 (2018)

[55] Podgornik B, Kafexhiu F, Kosec T, Jerina J, Kalin M. Friction and anti-galling properties of hexagonal boron nitride (h-BN) in aluminium forming. Wear 388-389: 2-8 (2017)

[56] Hollerweger R, Riedl H, Paulitsch J, Arndt M, Rachbauer R, Polcik P, Primig S, Mayrhofer P H. Origin of high temperature oxidation resistance of Ti-Al-Ta-N coatings. Surf Coat Technol 257: 78-86 (2014)

[57] Kubota K, Ohba T, Morito S. Frictional properties of new developed cold work tool steel for high tensile strength steel forming die. Wear 271(11-12): 2884-2889 (2011)

[58] Shen L, Zhou J, Xiong Y B, Zhang J S, Meng Y. Analysis of service condition of large hot forging die and refabrication of die by bimetal-layer weld surfacing technology with a cobalt-based superalloy and a ferrous alloy. J Manuf Process 31: 731-743 (2018)

[59] US-ASTM. ASTM G98-02 Standard test method for galling resistance of materials. ASTM, 2002.

[60] Hummel S R, Helm J. Galling 50 , a stochastic measure of galling resistance. J Tribol 131(3): 034502 (2009)

[61] US-ASTM. ASTM G196-08 Standard test method for galling resistance of material couples. ASTM, 2008.

[62] Harsha A P, Limaye P K, Tyagi R, Gupta A. Development of tribological test equipment and measurement of galling resistance of various grades of stainless steel. J Tribol 138(2): 024501 (2016)

[63] Hawryluk M, Ziemba J, Sadowski P. A review of current and new measurement techniques used in hot die forging processes. Meas Control 50(3): 74-86 (2017)

[64] Dimla E. Dimla S. Sensor signals for tool-wear monitoring in metal cutting operations-A review of methods. Int J Mach Tools Manuf 40(8): 1073-1098 (2000)

[65] Hawryluk M, Kaszuba M, Gronostajski Z, Sadowski P. Systems of supervision and analysis of industrial forging processes. Eksploat Niezawodn-Mainten Reliab 18(3): 315-324 (2016)

[66] Groche P, Brenneis M. Manufacturing and use of novel sensoric fasteners for monitoring forming processes. Measurement 53: 136-144 (2014)

[67] Kim S Y, Ebina A, Sano A, Kubota S. Monitoring of process and tool status in forging process by using bolt type piezo-sensor. Procedia Manuf 15: 542-549 (2018)

[68] Moghadam M, Christiansen P, Bay N. Detection of the onset of galling in strip reduction testing using acoustic emission. Procedia Eng 183: 59-64 (2017)
[69] Dardona S, Shen A, Tokgöz Ç. Direct write fabrication of a wear sensor. IEEE Sens J 18(8): 3461-3466 (2018)

[70] Thomsen E G, MacDonald A G, Kobayashi S. Flank friction studies with carbide tools reveal sublayer plastic flow. J Eng Ind 84(1): 53-62 (1962)

[71] Shaw M C, Ber A, Mamin P A. Friction characteristics of sliding surfaces undergoing subsurface plastic flow. $J$ Basic Eng 82(2): 342-345 (1960)

[72] Groche P, Kramer P, Bay N, Christiansen P, Dubar L, Hayakawa K, Hu C, Kitamura K, Moreau P. Friction coefficients in cold forging: A global perspective. CIRP Ann 67(1): 261-264 (2018)

[73] Vierzigmann H U, Merklein M, Engel U. Friction conditions in sheet-bulk metal forming. Procedia Eng 19: 377-382 (2011)

[74] Bay N, Eriksen M, Tan X, Wibom O. A friction model for cold forging of aluminum, steel and stainless steel provided with conversion coating and solid film lubricant. CIRP Ann 60(1) 303-306 (2011)

[75] Wang Z G, Yoshikawa Y, Suzuki T, Osakada K. Determination of friction law in dry metal forming with DLC coated tool. CIRP Ann 63(1): 277-280 (2014)

[76] Doege E, Alasti M, Schmidt-Jürgensen R. Accurate friction and heat transfer laws for enhanced simulation models of precision forging processes. J Mater Process Technol 150: 92-99 (2004)

[77] Lüchinger M, Velkavrh I, Kern K, Baumgartner M, Klien S, Diem A, Schreiner M, Tillmann W. Development of a constitutive model for friction in bulk metal forming. Lubricants 6(2): 42 (2018)

[78] Cocks M. Interaction of sliding metal surfaces. $J$ Appl Phys 33(7): 2152-2161 (1962)

[79] Suh N P. An overview of the delamination theory of wear. Wear 44(1): 1-16 (1977)

[80] Sasada T, Izumi T. Mutual transfer and wear in virgin/virgin surface rubbing: Confirmation of the reality of adhesive wear and a negative assertion for fatigue wear concept. (in Japanese). J Jpn Soc Tribol 49(12): 954-961 (2004)

[81] Yanagida A, Azushima A. Evaluation of coefficients of friction in hot stamping by hot flat drawing test. CIRP Ann 58(1): 247-250 (2009)

[82] Archard J F, Hirst W. The wear of metals under unlubricated conditions. Proc Roy Soc A Math Phys Eng Sci 236(1206): 397-410 (1956)

[83] Oyane M. A testing method for evaluating metal sticking to tool surface and tool wear-investigation into compatibility between work material and tool material in metal forming I-. (in Japanese). J Jpn Soc Technol 
Plast 20(222): 644-651 (1979)

[84] Groche P, Moeller N, Hoffmann H, Suh J. Influence of gliding speed and contact pressure on the wear of forming tools. Wear 271(9-10): 2570-2578 (2011)

[85] Deng L, Pelcastre L, Hardell J, Prakash B, Oldenburg M. Experimental evaluation of galling under press hardening conditions. Tribol Lett 66(3): 93 (2018)

[86] Kitano H, Dohda K, Kalin M, Ehmann K F. Galling growth analysis in metal forming. Manuf Lett 16: 32-35 (2018)

[87] Usui E, Shirakashi T, Kitagawa T. Analytical prediction of three dimensional cutting process-Part 3: Cutting temperature and crater wear of carbide tool. J Eng Ind 100(2): 236-243 (1978)

[88] Goyal A, Dhiman S, Kumar S, Sharma R. A study of experimental temperature measuring techniques used in metal cutting. Jordan J Mech Ind Eng 8(2): 82-93 (2014)

[89] Werschmoeller D, Ehmann K, Li X C. Tool embedded thin film microsensors for monitoring thermal phenomena at tool-workpiece interface during machining. J Manuf Sci Eng 133(2): 021007 (2011)

[90] Li L W, Li B, Ehmann K F, Li X C. A thermomechanical model of dry orthogonal cutting and its experimental validation through embedded micro-scale

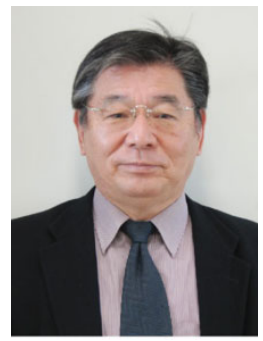

Kuniaki DOHDA. He is the Dr. of Eng. (Nagoya University) and a professor of the Department of Mechanical Engineering, Northwestern University, USA. His main research interests are in the in-

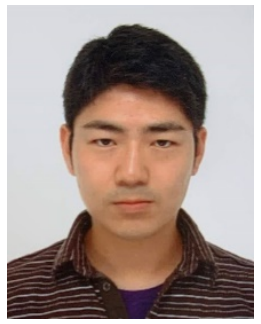

Masahito YAMAMOTO. He received his doctoral degree in mechanical engineering from the Tokyo University of Agriculture and Technology, Japan in 2008. thin film thermocouple arrays in PCBN tooling. Int $J$ Mach Tools Manuf 70: 70-87 (2013)

[91] Matsushita M, Kitani Y, Ikeda R, Ono M, Fujii H, Chung Y D. Development of friction stir welding of high strength steel sheet. Sci Technol Weld Join 16(2): 181-187 (2011)

[92] Shamanian M, Mostaan H, Safari M, Szpunar J A. Friction stir modification of GTA 7075-T6 Al alloy weld joints: EBSD study and microstructural evolutions. Arch Civ Mech Eng 17(3): 574-585 (2017)

[93] Woo W, Feng Z, Wang X L, Brown D W, Clausen B, An $\mathrm{K}$, Choo H, Hubbard C R, David S A. In situ neutron diffraction measurements of temperature and stresses during friction stir welding of 6061-T6 aluminium alloy. Sci Technol Weld Join 12(4): 298-303 (2007)

[94] Yoshikawa G, Miyasaka F, Hirata Y, Katayama Y, Fuse T. Development of numerical simulation model for FSW employing particle method. Sci Technol Weld Join 17(4): 255-263 (2012)

[95] Fehrenbacher A, Duffie N A, Ferrier N J, Pfefferkorn F E, Zinn M R. Effects of tool-workpiece interface temperature on weld quality and quality improvements through temperature control in friction stir welding. Int J Adv Manuf Technol 71(1-4): 165-179 (2014)

terrelated area of metal forming, process tribology, surface engineering, and micro-manufacturing. Currently, he is the president of IRGTM, IFMM, and GRGLMM. He is a fellow of ASME, JSME, and JSTP.

He is currently working as an assistant manager of NSK Ltd. His research interests include working towards understanding the galling mechanism and related wear phenomena. 


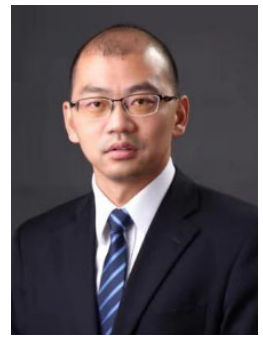

Chengliang HU. He is a professor in the Institute of Forming Technology and Equipment, Shanghai Jiao Tong University, China. $\mathrm{He}$ is part of the National Engineering Research Center of

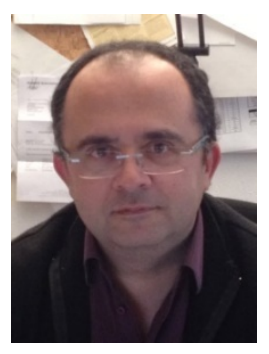

Laurent DUBAR. He is a professor at the Polytechnic University Hauts de France in France. He is head of the Lab. LAMIH UMR CNRS 8201 (250 researchers). His research activities are in the field of metal forming, with a focus on Multi

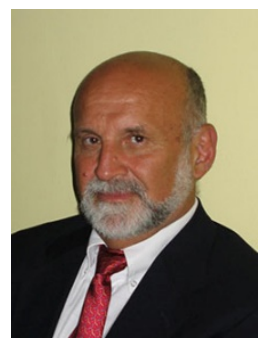

Kornel F. EHMANN. He is a professor of the Department of Mechanical Engineering, Northwestern University, USA. His main
Die and Mold CAD. He has more than 10 years' research experience working in areas of precision forging processing technologies. As the leader, he has managed 20 research projects sponsored by NSFC, MIIT, and industrial companies.

Scale Tribology of Processes: friction measurement, wear of tooling, lubrication modeling; at room and high temperature. He is Chairman of International Cold Forging Group (ICFG). He is also a member of the Carnot Arts Institute and is a professor of the Polytechnic University of Hauts-de-France.

research interests are in machine tool and metal cutting dynamics, accuracy control in machining, and micromanufacturing. He is a fellow of ASME, SME, and ISNM. 